\title{
Highlights
}

An Observation of Non-stationary Response to Non-synoptic Wind on the Forth Road Bridge

John S Owen, Dinh Tung Nguyen, Xiaolin Meng, Panagiotis Psimoulis, Yilin Xie

- Presents evidence from field monitoring of the non-stationary response of a long span bridge to wind loading

- Presents evidence associating intense rainfall radar data with observed nonstationary large amplitude response

- Demonstrates the added value of using GNSS sensors to monitor the deflection of large structures under wind load 


\title{
An Observation of Non-stationary Response to Non-synoptic Wind on the Forth Road Bridge
}

\author{
John S Owen a,*, Dinh Tung Nguyen ${ }^{\mathrm{a}}$, Xiaolin Meng ${ }^{\mathrm{a}}$, Panagiotis Psimoulis ${ }^{\mathrm{a}}$, \\ Yilin $\mathrm{Xie}^{\mathrm{a}}$ \\ ${ }^{a}$ Faculty of Engineering, University of Nottingham, University Park, Nottingham, NG7 2RD, UK
}

\begin{abstract}
The GeoSHM project feasibility study for monitoring the Forth Road Bridge is briefly introduced and the instrumentation summarised. The events of January $9^{\text {th }} 2015$ are described, when the bridge was struck by storm Elon, which caused widespread damage across Scotland and led to the temporary closure of the bridge when a van was blown over. During this storm an anomalous large amplitude response was observed.
\end{abstract}

The data for January $9^{\text {th }} 2015$ are analysed to show that the extreme response and the corresponding wind are non-stationary and non-Gaussian. Further analysis of the rainfall radar data for the same time shows a line of intense rainfall extending for over $100 \mathrm{~km}$, which passes the site of the bridge at exactly the time of the peak response. The rainfall intensity was high enough to indicate that this feature was caused by convective activity and this observation was corroborated by records of lightning strikes. It is concluded that non-stationary wind events can give rise to large response of long span bridge structures and that this response can exceed that observed from the stationary wind field. Furthermore, historical data confirm that energetic squall lines are not uncommon in the UK. Therefore, the assumption of stationarity in predicting the wind induced response of long span bridges may be non conservative and the climatology of large convective systems, such as squall lines, should be considered in assessing the wind hazard for these structures.

Keywords: Non-stationary response, Wind, Suspension Bridge, GNSS, Structural Health Monitoring

\footnotetext{
${ }^{*}$ Corresponding author
} 


\begin{abstract}
The GeoSHM project feasibility study for monitoring the Forth Road Bridge is briefly introduced and the instrumentation summarised. The events of January $9^{\text {th }} 2015$ are described, when the bridge was struck by storm Elon, which caused widespread damage across Scotland and led to the temporary closure of the bridge when a van was blown over. During this storm an anomalous large amplitude response was observed.

The data for January $9^{\text {th }} 2015$ are analysed to show that the extreme response and the corresponding wind are non-stationary and non-Gaussian. Further analysis of the rainfall radar data for the same time shows a line of intense rainfall extending for over $100 \mathrm{~km}$, which passes the site of the bridge at exactly the time of the peak response. The rainfall intensity was high enough to indicate that this feature was caused by convective activity and this observation was corroborated by records of lightning strikes. It is concluded that non-stationary wind events can give rise to large response of long span bridge structures and that this response can exceed that observed from the stationary wind field. Furthermore, historical data confirm that energetic squall lines are not uncommon in the UK. Therefore, the assumption of stationarity in predicting the wind induced response of long span bridges may be non conservative and the climatology of large convective systems, such as squall lines, should be considered in assessing the wind hazard for these structures.
\end{abstract}

\title{
1. Introduction
}

\subsection{Non-synoptic Winds}

The damaging effects of non-synoptic winds such as tornadoes are well known, but in many parts of the world non-synoptic winds are neglected in codes of practice. This is especially the case in north west Europe, where it has been assumed that the extreme wind climate is dominated by synoptic storms driven by north Atlantic depressions. This has allowed the design process to consider both the wind field and structural response to be stationary random processes and hence the gust factor approach can be adopted.

The limitations of these assumptions have become an increasing cause for concern in recent years and over the last two decades there has been a lot of research focussed on better understanding the importance of non-synoptic winds. These typically give rise to different profiles of mean and turbulent wind speeds with height. The time varying nature of the fluctuating wind speed is also different, 
typically being non-stationary, which influences the choice of method used to predict the response of structures. For non-stationary winds, it is necessary to perform the response in the time domain (Cao and Sarkar, 2015) or to create a time varying representation of the wind spectum (Huang et al., 2015; Tao et al., 2017; Tao and Wang, 2019). It has also been noted that the cross wind correlation winds, a factor that could be particularly relevant for long span structures (Holmes et al., 2008).

Significant effort has been made to produce realistic small scale physical simulations of non-synoptic winds including tornadoes (Haan Jr et al., 2008; Mishra down-bursts (Jesson et al., 2015a,b; Romanic et al., 2019; Hangan et al., 2019). Other research has considered the numerical simulation of these phenomena (Chen and Letchford, 2007; Lompar et al., 2018; Orf et al., 2012, 2014). The aim of both physical and numerical simulations is to obtain details of the local wind field during these events because full scale data is hard to obtain. Other research has considered the processing of field measurements of wind speed data to identify and classify non-stationary, non-synoptic events (De Gaetano et al., 2014; Zhang et al., 2017) and to produce empirical models of non-stationary wind profiles (Chen and Letchford, 2005, 2006). Burlando et al. (2017) have analysed in detail multiple recordings of a thunderstorm downburst around the port of Genoa and compared the results with other historical records in terms of the meteorological context and characterisation for engineering applications.

A number of cases of damage to power lines from non-synoptic winds have been reported leading to the recognition that these winds pose a significant threat to field data from a number of long span bridges has shown that the incident wind field is frequently non-stationary (Li et al., 2010; Wang et al., 2016). However, there is very limited full scale data available to show the influence of non-synoptic winds on large infrastructure assets such as long span bridges. Hence, observations of non-stationary response of these structures are very useful to show both the significance of this loading and to provide data for the validation of numerical and physical simulations.

\subsection{The Forth Road Bridge and GeoSHM Project}

The Forth Road Bridge (FRB) is a major suspension bridge crossing the Firth of 
and a total crossing length of over $2.5 \mathrm{~km}$, the bridge was the fourth longest in the world when it was opened in 1964. The main stiffening girder is formed from two parallel steel trusses $23.774 \mathrm{~m}$ apart centre to centre and $18.124 \mathrm{~m}$ deep between chord centrelines. Lateral and torsional stiffening is provided by horizontal trusses between the chords of the edges girders and by regular cross frames. The deck is formed from steel orthotropic plates in the main span and a composite concrete slab on steel beams in the side spans. The girder also carries two footways outside the line of the main girder, bringing the overall width of the deck to $36.026 \mathrm{~m}$. There are three longitudinal air gaps at roadway level (between each footway and carriageway and between the two carriageways), which were included to improve aerodynamic stability.

In 2014, the FRB was chosen as the test case for a feasibility study on GNSS and Earth Observation for Structural Health Monitoring (GeoSHM), a project funded by the European Space Agency (ESA) to develop a structural health monitoring system exploiting satellite technology. In this feasibility study, a limited set of instrumentation was installed on the FRB and data was collected between August 2013 and March 2015. The feasibility study was successful and ESA subsequently funded a demonstration project, in which a full set of instrumentation has been installed on the FRB and further instrumentation installed on two large bridges in China (Meng et al., 2018).

Scotland enjoys a vigorous wind climate. For structural design, this is assumed to be dominated by synoptic winds with extreme winds arising from North Atlantic depressions. A typical storm, storm Elon, occurred on the night of January $8^{\text {th }}$ and $9^{\text {th }} 2015$, with a deep low pressure system passing to the North of Scotland, Figure 3. However, when the GeoSHM data were examined following this particular storm, it was observed that the peak bridge displacement did not lie on the longterm trend. This provided the motivation for the further investigations, which are outlined in this paper. These considered the hypothesis that the peak response was non-stationary and the result of the bridge being struck by a non-synoptic feature within the wind storm. The possible causes of this non-synoptic feature and the climatology of such events were also considered to assess whether they might be significant for the design of large structures.

The aim of this paper is simply to present a case study on the influence of nonsynoptic wind phenomena on a long span bridge. The paper will first summarise 105 the field monitoring data from the FRB, considering in detail the response on January $9^{\text {th }} 2015$. It will then consider rainfall radar data and records of lightning 
strikes to identify possible convective activity during the storm. Finally, it will briefly review the meteorological background and climatology in order to consider the significance of the phenomenon causing the observed response for both design and operation of large infrastructure.

\section{Bridge Monitoring}

\subsection{Instrumentation}

The instrumentation for the feasibility study consisted of two Global Navigation Satellite System (GNSS) receivers located on either side of the bridge deck at mid span. A third GNSS receiver was installed at the top of the South West pylon and a fourth, reference, receiver was located on the roof of the bridge control building on the south side of the crossing. The GNSS receivers used were Leica model GR10 with $10 \mathrm{~Hz}$ sampling rate and a kinematic accuracy of $10 \mathrm{~mm} \pm 1 \mathrm{ppm}$ horizontally and $20 \mathrm{~mm} \pm 1 \mathrm{ppm}$ vertically. The GNSS receivers were linked to a server in the bridge control room, from where data were transferred to the University of Nottingham via the internet.

Although no anemometers were installed as part of the initial feasibility study, access was available to data from two anemometers belonging to the bridge operator. Both of these anemometers were Vaisala WMT700 WINDCAP Ultrasonic Wind Sensors. One anemometer (ANE-MS) was installed on the east side of the main span at mid span and the second (ANE-NW) was located on the north side span close to the side tower. ANE-MS provided 30 second mean wind speed data and the maximum three second gust wind speed occurring in each 30 second period. Wind speeds were reported in miles per hour ( $\mathrm{mph}$ ) with a precision of $1 \mathrm{mph}$ and have been converted to $\mathrm{ms}^{-1}$ for this paper. The wind direction was also recorded for each 30 second period, but only in 8 cardinal directions. ANE-NW provided similar summary statistics, but based on a 10 minute averaging period.

\subsection{Response to Wind, Long Term Trends During Feasibility Study}

The data from the GNSS receivers at midspan were used to estimate the lateral, 135 vertical and pitching response of the bridge. First, the data were transformed from the GNSS coordinate system to a local system defined by the bridge axis. The lateral and vertical response were each estimated by taking the average of the displacements on the two sides of the deck and the pitch by considering the normalised difference between the vertical displacements on the two sides. 
Both the vertical and pitching response were highly sensitive to temperature and traffic loading, showing daily, diurnal, weekly and annual trends. These trends are predominantly caused by the sag of the bridge due to thermal expansion and the weight of traffic and they mask the effects of the wind. Therefore, this paper will focus on the lateral response, which was relatively unaffected by the sag caused by temperature and traffic. Future papers will consider the separation of wind, traffic and temperature effects using artificial neural networks and surrogate models.

The bridge response and wind data were divided into ten minute records and these were used to summarise the long term response during the feasibility study. Figure 4 shows the mean, peak and RMS lateral displacement of the bridge at midspan plotted against the component of the mean wind speed normal to the bridge deck at mid span for the whole of 2015. There is a clear second order trend for each of these terms, which is to be expected from quasi steady theory. Here, it is important to note one advantage of measuring displacements compared to accelerations is that it is possible to to determine the mean response for a ten minute record as well as the dynamic components. This has the additional benefit that a simple curve fit can be used to establish the value of drag coefficient for the full scale bridge deck $\left(C_{D}=0.297\right.$ from this field data, compared to $C_{D}=0.232$ used in design and $C_{D}=0.286$ obtained by the University of Glasgow in more recent wind tunnel tests).

For the mean data in Figure 4, there appear to be two further trends above and below the main trend. These occur because the coarse resolution used to record the wind direction during the feasibility study can lead to the normal component of wind from the prevailing wind direction being misrepresented. The prevailing wind lies between west and south west and so there are a large number of 10 minute records where the mean wind direction lies close to $247.5^{\circ}$, the boundary between these two sectors. Some of these will be classified as westerly, exaggerating the normal component of wind speed by up to $8 \%$, leading to the lower band of data points in Figure 4. Other records will be classified as south westerly, leading to the normal component of the wind speed being under estimated by up to $22 \%$ leading to the higher band of data points in Figure 4.

Using the 10 minute data presented in Figure 4, it is possible to estimate a mean gust response factor for the lateral displacement at mid span by taking the ratio of the peak response $\hat{y}$ to the mean response $\bar{y}$. The mean gust response factor of all the records with a mean wind speed greater than $5 \mathrm{~ms}^{-1}$ was found to be 1.38 and its median value was 1.31. The corresponding peak factor $k_{p}$ was also found by 
dividing the difference between the peak and mean displacement by the standard deviation $\sigma_{y}$. The mean peak factor of all the records with a mean wind speed greater than $5 \mathrm{~ms}^{-1}$ was found to be 2.87 and its median value was 2.83 .

One point is high-lighted in each of the charts in Figure 4. The mean, peak and RMS displacement for this ten minute record are all significantly larger than expected from the relevant trends for the corresponding mean wind speed. Furthermore, the gust factor for this record is found to be 2.09, which is noticeably higher than that for the long term average, although the peak factor of 2.88 is consistent with the average. This point looks like an outlier and it would be easy to dismiss this as a measurement error. However, further investigation indicates that this data point corresponds to a significant non-synoptic wind event. This will be discussed further below.

\subsection{Response to Wind on January $9^{\text {th }} 2015$}

The anomalous response noted above occurred shortly after midnight on January $9^{\text {th }}$ 2015. Figure 5 shows the mean, RMS and peak lateral displacements for 10 minute records on Thursday January $8^{\text {th }}$ and Friday January $9^{\text {th }} 2015$. There are some gaps in the data corresponding to times when the internet connection between the FRB and University of Nottingham was lost, however the response to storm Elon can clearly be seen in both the mean and dynamic behaviour of bridge. The bridge response data indicate that the storm had a significan effect on the bridge from about 23:00 UTC on Thursday $8^{\text {th }}$ until about 11:00 UTC on Friday $9^{\text {th }}$ (all times are UTC, which coincides with local time during this event). The lateral displacement increased rapidly after 23:00 UTC, with the peak response occurring at about 00:36 UTC, which corresponds to the anomalous record noted above.

Further evidence of the effect of the wind is shown in Figure 6, which shows a van that was reported to have been blown over by a large gust of wind while crossing the bridge at 00:36 UTC. This occurred even though the bridge had already been closed to high sided vehicles because of the forecast for high winds. Following this incident, the bridge was closed to all vehicles until 07:00 UTC the next morning.

Figure 7 shows the lateral and vertical responses recorded on the bridge between 00:00 UTC and 01:00 UTC on Friday January $9^{\text {th }}$. The figure shows the overall response and also a smoothed dataset obtained using a 1 minute moving average, which provides an approximate measure of the background response. The window 
length of 1 minute was chosen to reduce the response at the first natural frequency to a negligible level. The moving average acts as a simple low pass filter in the time domain with a cut off frequency in this case of c. $0.017 \mathrm{~Hz}$, well below the natural frequencies of the first lateral $(0.069 \mathrm{~Hz})$ and first vertical $(0.102 \mathrm{~Hz})$ modes.

The two most striking features of this figure are the sudden large and rapid change in the moving average of the lateral response at about 00:36 UTC and the associated large dynamic response. The moving average changes by $0.862 \mathrm{~m}$ in less than 2 minutes; considering that the moving average process will tend to smooth out abrupt changes, this indicates a step change in mean response. This rapid increase in quasi static displacement is followed by an extreme dynamic response in the first lateral vibration mode with a peak to peak amplitude of almost $3 \mathrm{~m}$ (Figure 8). This transient response then decays over a period of three minutes from a maximum of $3 \mathrm{~m}$ peak to peak to almost zero (Figure 9). The shape of the decay indicates that this is the effect of the short rise time for the gust and subsequent (smaller) fluctuations in wind speed have little impact on the decay. This behaviour is typical of the response of a single degree of freedom system to a step excitation and suggests that the bridge was hit by a very large gust of wind, with a very sharp initiation and a duration of several minutes. Although there is no direct evidence to support the supposition, it can also be inferred that the gust had significant spatial extent in order to excite the first lateral vibration mode like this.

Both the moving average and dynamic components of the response of the bridge appear to be non-stationary during the one hour period between 00:00 UTC and 01:00 UTC. The augmented Dickey-Fuller unit root test is a straightforward method to test the stationarity of a time series and is available within Matlab and other statistics packages. Applying the augmented Dickey-Fuller test to the data presented in Figure 7 confirms that the moving average of the response is nonstationary at the $5 \%$ significance level for both the lateral and vertical displacements. Although applying the test to the lateral and vertical dynamic responses in Figure 8 indicates that they are both stationary for the 1 hour duration, the ten minute records shown in Figure 9 are both found to be non-stationary at the $5 \%$ significance level. This is important when considering the prediction of the peak response. Predictions of peak response based on assumptions of stationarity, such as the application of a gust response factor to the mean, will underestimate the likely peak response for non-stationary events like the current case. 


\section{Wind and Weather Data}

\subsection{Anemometer Data}

Figure 10 shows the 30 second mean wind speed and direction during January $8^{\text {th }}$ and $9^{\text {th }}$. The 30 second moving mean wind speed has been used previously in investigations of thunderstorm wind events (Burlando et al., 2017) because it enables slowly varying flow features to be extracted. The wind storm can clearly be seen from this record, starting late in the evening on the $8^{\text {th }}$ and reducing to calm conditions in the afternoon of the $9^{\text {th }}$. The steady increase in wind speed during the first few hours of the storm should be noted and also the strong peak that occurs just after midnight. Examining this part of the record more closely, Figure 11, reveals that the maximum 30 second mean occurs just after 00:36 UTC, coinciding with the onset of the dynamic response shown in Figure 9. The mean wind speed increases by $\sim 6 \mathrm{~ms}^{-1}$ in 90 seconds reaching a maximum value of $33.5 \mathrm{~ms}^{-1}$. At the same time, the maximum gust speed within the 30 second record reaches $40.7 \mathrm{~ms}^{-1}$.

Further analysis of the 1 hour record containing the peak gust found that the 60 minute mean wind speed was $25.6 \mathrm{~ms}^{-1}$. Hence the 60 minute gust factor was 1.59, which is consistent with values in the literature (ESDU, 1983; Durst, 1960; Cao et al., 2009) for major cyclonic systems. This 60 minute gust factor is notably smaller than the gust factors for thunderstorms and gust fronts reported by De Gaetano et al. (2014) and is typical of their Depression classification for a stationary Gaussian storm. However, performing a runs test on the 30 second mean wind speed data for this 1 hour record showed that the wind speed was non-stationary at the $5 \%$ significance level and, furthermore, the KolmogorovSmirnov test showed that the data was non-Gaussian at the $5 \%$ significance level. Considering the classification system proposed in De Gaetano et al. (2014), a nonstationary non-Gaussian record is consistent with a thunderstorm. Values of skewness and kurtosis, indicated that the 60 minute record was mildly non-Gaussian. The skewness (0.60) was consistent with the thunderstorm records presented by De Gaetano et al. (2014) whereas the kurtosis (2.59) was more consistent with their depression records.

As mentioned earlier, only limited direction data is available in the records provided by the bridge authority. The direction of the wind during the first part of the storm remains steadily within the SW sector. After 00:37:30, when the maximum wind speed is reached, there is an abrupt change in wind direction to the $\mathrm{W}$ sector (Figure 11). Whether this is a significant change or simply a small variation 
that moves the direction from one sector to the other cannot be determined. The change does, however, coincide precisely with the main gust and the new direction is maintained almost continuously until the end of the storm. A number of studies report a step change in the wind direction when a non-stationary non-Gaussian thunderstorm passes an anemometer, typically of about $90^{\circ}$ (Burlando et al., 2017; De Gaetano et al., 2014; Sherman, 1987). The smaller change in wind direction observed in the current data may be a result of the strong background wind associated with the weather system.

\subsection{Rainfall Radar Images}

The bridge response data presented above indicate that on the early morning of January $9^{\text {th }} 2015$ the FRB exhibited a large non stationary response. The nature of the behaviour was typical of a step response, indicating that the bridge was hit by a large coherent gust. Analysis of the limited amount of wind data available from the anemometer used by the FRB bridge operator has shown that there was a major storm blowing at this time and that the peak wind speed measurement occurred at the time of the non-stationary bridge response. Furthermore, wind data for the hour in which the large response occurred are both non-stationary and non-Gaussian, which would typically be associated with significant convective activity. Figure 3 shows a convergence line lying across northern Scotland, a feature often associated with strong convection, but for further direct evidence of convective activity such as thunderstorm down-bursts it is helpful to examine the rainfall data.

Convective cells often lead to short periods of intense rainfall and so an indication as to whether there was significant convective activity at the time can be found by examining the rainfall radar data. Table 1 shows the classification of rainfall by intensity used by the UK Met Office. Assuming that most violent rain showers develop from some form of convective cell, a rainfall intensity greater than $50 \mathrm{mmh}^{-1}$ can be used as an indicator (but not a proof) of convective activity.

Rainfall radar data for the UK is available from the UK Met Office both for individual radar stations and as a composite data set combining all radar stations. The data is available for research purposes from the data archive of the Centre for Environmental Data Analysis in $5 \mathrm{~km}, 2 \mathrm{~km}$ and $1 \mathrm{~km}$ resolution grids. To investigate the contribution of convective activity to the observed non-stationary response of the FRB, a series of composite rainfall radar images at five minute intervals from 00:00 UTC to 01:00 UTC with a resolution of $1 \mathrm{~km}$ were studied. 
Figure 12 shows a series of 4 rainfall radar images for the whole of Great Britain from 00:15 UTC through to 01:00 UTC on January $9^{\text {th }} 2015$. These images show a band of rain lying south west-north east across central Scotland, which coincides to the occluded front shown in the synoptic chart in Figure 3. This band of rain progresses Eastwards though the sequence of images, passing the FRB between 00:30 UTC and 00:45 UTC, the time at which the non-stationary response was observed.

Within this broader band of rain, a narrower and more intense line of heavy rainfall can be seen on its trailing edge. This feature can be seen more clearly when the scale is increased as shown in Figure 13, which covers a $100 \mathrm{~km}$ square centred on the FRB at five minute intervals. The narrow line of intense rainfall can be seen passing the location of the FRB between 00:35 and 00:40. This line of intense rainfall lies on a bearing of $55^{\circ}$ at the time that it passes the FRB. The peak values of rainfall intensity within this square and over the whole of the UK are listed in Table 2. These values show that there were violent showers in the area of the FRB at the time when the non-stationary response was measured, indicating strongly that this response was due to convective activity.

view is further confirmed by examining records of lighting strikes. Figure 14 shows the record of lightning strikes across north west Europe for the 24 hours up to 14:30 UTC on January $9^{\text {th }}$. This shows thunderstorms moving from the west of Scotland across the North Sea and into Germany. Looking more closely at the lighting strikes in Scotland (Figure 15) it can be seen that there were several lightning strikes in the Forth Estuary at just the time that the non-stationary response was onserved on the bridge.

Figure 16 shows all the high intensity rainfall radar data for the period 00:00 UTC to 01:00 UTC overlaid on the same map. This figure reveals the predominant direction of travel of the convective activity, which is not aligned with the line of intense rainfall, but is almost due East with a bearing of $85^{\circ}$. From this figure it is also possible to estimate the speed of the line of intense rainfall as it passes the bridge, which is $\sim 120 \mathrm{kmh}^{-1}$ or $\sim 33 \mathrm{~ms}^{-1}$. It is noted that (i) the change from $55^{\circ}$ to $85^{\circ}$ is consistent with the observed change in wind direction from SW to $\mathrm{W}$ as the line of intense rainfall passes the bridge and (ii) the speed of this line is approximately equal to the 30 second mean wind speed at this time. 


\subsection{Meteorology and Climatology}

The patterns of intense rainfall shown in Figures 12 and 13 are characteristic of phenomena known as squall lines (Rauber and Ramamurthy, 2015) or convective lines. Mid latitude squall lines are meteorological features that are associated with extended lines of meso-scale convective systems, often lines of fast moving thunderstorms (Laing, 2015). They typically extend for several hundred kilometres and are known to occur in different seasons and in varying meteorological conditions, including mid latitude winter storms (strong migrating low pressure systems) (Parker, 2015). There is considerable variation in the terminology used to describe these features, both in the field and in the literature. Although most observations describe the convective line at the leading edge of a broader shelf of stratiform cloud, a significant number observe the convective line at the trailing edge (Rauber and Ramamurthy, 2015), as in the rainfall radar images presented above. Squall lines are known to be long lived, fast moving and capable of creating widespread damaging winds (Parker, 2015).

The extended line of convective activity creates a gust front of sustained strong winds (Rotunno, 2015). These are often referred to as straight line winds to differentiate them the more localised non-stationary winds associated with tornadoes and isolated up-drafts and down-drafts. Straight line winds associated with squall lines can also be differentiated from those associated with large scale cyclonic systems as the gust front has a more three-dimensional wind system. Squall lines are reported to cause widespread damage, which often occurs in coherent patterns over many hundreds of kilometres. These are then referred to as derechoes, a derecho typically giving rise to swathes of damage associated with bow echoes in the squall line (Laing, 2015).

Bow echoes are phenomena observed in rainfall radar images, where the linear formation of the squall line deflects into a curved shape when the effect of downburst winds causes significant inflow into the rear of the system (Weisman, 2015). Importantly, bow echoes are often associated with the strongest and most damaging winds within a squall line. In Figure 13, the convective line can be seen to be curved both to the north and the south of the FRB location, indicating the possible formation of bow echoes. This is especially evident in the data for 00:35 as the line passes the bridge site. The apparent gap in the high intensity rainfall at the bridge site could therefore be associated with the outflow from these features. Strongly bowed squall lines and those with notches are also often associated with other convective events, such as tornadoes. 
The evidence of the rainfall radar indicates that the extreme response of the FRB was due to the passing of a gust front associated with an extended squall line. Traditional approaches to modelling the wind hazard for codes in the United Kingdom have assumed that frontal thunderstorms are "suppressed when the external wind speed is high" (Cook, 1985). The evidence of the current case suggests that this assumption is not justified and it is therefore important to consider whether this is a rare event or whether it is likely to recur with significant frequency. There are a number of studies of the climatology of squall lines, convective lines and derechoes, both in the UK (Clark, 2013) and in Europe (Gatzen, 2004; Gatzen et al., 2011; Gatzen, 2011). These studies show that narrow rain bands occur frequently in both the UK and Germany and that these often show convective activity. For these events, lighting is often observed and damage is often reported. It is therefore important that these phenomena should be properly accounted for in the wind loading codes.

\section{Concluding Remarks}

During a period of high winds lasting several hours on the night of January $8^{\text {th }} / 9^{\text {th }}$ 2015, the Forth Road Bridge (FRB) was struck by one significant large gust typified by a rapid rise in wind speed, a duration of several minutes and a spatial extent hat was sufficient to excite a large dynamic response in the first lateral vibration mode, with a peak to peak displacement of $3 \mathrm{~m}$. The lateral response during this part of the storm was found to be non-stationary and the peak response occurred during this isolated event. Although there is very limited data, the motion of the bridge on January $9^{\text {th }}$ reveals important issues that could have significant consequence for accepted practice in the design and analysis of long span bridges and other wind sensitive structures:

1. Methods that assume stationarity are possibly non-conservative because they will not predict the extreme peak dynamic response observed here

2. The emphasis on small scale non-stationary features (thunderstorm downbursts, tornadoes etc.) in much current research may miss significant nonstationary events occurring along squall lines, which may be particularly important for large extended or tall structures

3. Squall lines are observable in rainfall radar, which can therefore be used to identify and classify events that aren't necessarily observed at meteorological stations. Rainfall radar data could also be used to provide advance warning to the owners and operators of large infrastructure assets 
4. There remains a pressing need to understand better the non-synoptic wind climate and to consider even mid latitude temperate regions as having a mixed wind climate when determining wind actions

425

The GeoSHM Feasibility and Demonstration projects were funded by the European Space Agency (ESA).

The authors are grateful to the erstwhile Forth Estuary Transport Authority (FETA) for access to the FRB during the feasibility study and to Transport Scotland and

The authors are grateful to the Centre for Environmental Data Analysis (CEDA) for access to the rainfall radar data from the Met Office Nimrod System (Met Office, 2003) and the mean sea level pressure charts (Met Office, 2015)

\section{References}

Al-Issa, A., El Ansary, A.M., Aboshosha, H., Aboutabikh, M., Ghazal, T., 2019. Evaluation of peak transmission line conductor reactions under downburst winds using optimization and simplified approaches. Frontiers in Built Environment 5. URL: https://www . frontiersin .org/article/10.3389/fbuil. 2019.00088, doi:10.3389/fbuil.2019.00088.

Burlando, M., Romanić, D., Solari, G., Hangan, H., Zhang, S., 2017. Field data analysis and weather scenario of a downburst event in livorno, italy, on 1 october 2012. Monthly Weather Review 145, 3507-3527. URL: https: //doi.org/10.1175/MWR-D-17-0018.1, doi:10.1175/mwr-d-17-0018.1.

Cao, B., Sarkar, P.P., 2015. Numerical simulation of dynamic response of a longspan bridge to assess its vulnerability to non-synoptic wind. Engineering Structures $84,67-75$.

Cao, S., Tamura, Y., Kikuchi, N., Saito, M., Nakayama, I., Matsuzaki, Y., 2009. Wind characteristics of a strong typhoon. Journal of Wind Engineering and Industrial Aerodynamics 97, 11-21. URL: http://www.sciencedirect. com/science/article/pii/S016761050800175X, doi:https://doi.org/ 10.1016/j . jweia.2008.10.002. 
Chen, L., Letchford, C.W., 2005. Proper orthogonal decomposition of two vertical profiles of full-scale nonstationary downburst wind speeds[lzcl]. Journal of Wind Engineering and Industrial Aerodynamics 93, 187-216.

Chen, L., Letchford, C.W., 2006. Multi-scale correlation analyses of two lateral profiles of full-scale downburst wind speeds. Journal of Wind Engineering and Industrial Aerodynamics 94, 675-696.

Chen, L., Letchford, C.W., 2007. Numerical simulation of extreme winds from thunderstorm downbursts. Journal of Wind Engineering and Industrial Aerodynamics 95, 977-990.

Clark, M.R., 2013. A provisional climatology of cool-season convective lines in the uk. Atmospheric Research 123, 180-196. URL: https: //www.scopus. com/inward/record.uri?eid=2-s2.0-84874348230\& do $i=10.1016 \% 2 f j$. atmosres $.2012 .09 .018 \& p a r t n e r I D=40 \& m d 5=$ 4e141508ad270adce9826e67c0d043bf, doi:10.1016/j.atmosres.2012. 09.018.

Cook, N.J., 1985. The desitgner's guide to wind loading of building structures Part 1. Butterworths.

De Gaetano, P., Repetto, M.P., Repetto, T., Solari, G., 2014. Separation and classification of extreme wind events from anemometric records. Journal of Wind Engineering and Industrial Aerodynamics 126, 132-143.

Durst, C.S., 1960. Wind speeds over short periods of time. The Meteorological Magazine 89, 181-187.

ESDU, 1983. Strong Winds in the Atmospheric Boundary Layer, Part 2: Discrete Gust Speeds. volume Item No. 83045. Engineering Sciences Data Unit, London.

Gatzen, C., 2004. A derecho in europe: Berlin, 10 july 2002. Weather and Forecasting 19, 639-645. doi:10 .1175/1520-0434 (2004)019<0639: ADIEBJ>2 . $0 . \mathrm{CO} ; 2$.

Gatzen, C., 2011. A 10-year climatology of cold-season narrow coldfrontal rainbands in germany. Atmospheric Research 100, 366370. URL: http://www.sciencedirect.com/science/article/pii/ 
S0169809510002565, doi:https://doi.org/10.1016/j.atmosres. 2010. 09.018 .

Gatzen, C., Púčik, T., Ryva, D., 2011. Two cold-season derechoes in europe. Atmospheric Research 100, 740-748. URL: http://www.sciencedirect. com/science/article/pii/S0169809510003297, doi:https://doi.org/ 10.1016/j. atmosres.2010.11.015.

Haan Jr, F.L., Sarkar, P.P., Gallus, W.A., 2008. Design, construction and performance of a large tornado simulator for wind engineering applications. Engineering Structures 30, 1146-1159.

Hangan, H., Romanic, D., Jubayer, C., 2019. Three-dimensional, nonstationary and non-gaussian (3d-ns-ng) wind fields and their implications to wind-structure interaction problems. Journal of Fluids and Structures 91, 102583. URL: http://www.sciencedirect.com/science/article/pii/ S0889974618308855, doi:https://doi.org/10.1016/j.jfluidstructs. 2019.01 .024$.

Holmes, J.D., Hangan, H.M., Schroeder, J.L., Letchford, C.W., Orwig, K.D., 2008. A forensic study of the lubbock-reese downdraft of 2002. Wind and Structures, An International Journal 11, 137-152. URL: https://www.scopus.com/inward/record. uri?eid=2-s2 . 0-46749119776\&doi=10.12989\%2f was . 2008.11 . 2. 137\&partner ID =40\&md5=d8d1286d726f $0 \mathrm{ca} 1 \mathrm{f} 47257 \mathrm{~b} 3 \mathrm{f} 08362 \mathrm{~d} 3$, doi:10.12989/was.2008.11.2.137.

Huang, G., Zheng, H., Xu, Y.l., Li, Y., $2015 . \quad$ Spectrum models for nonstationary extreme winds. Journal of Structural Engineering 141, 04015010. URL: https://ascelibrary.org/doi/abs/10. 1061/\%28ASCE\%29ST.1943-541X.0001257, doi:doi:10.1061/(ASCE)ST . $1943-541 \mathrm{X} .0001257$.

Ibrahim, I., El Damatty, A., Elawady, A., 2019. The dynamic effect of downburst winds on the longitudinal forces applied to transmission towers. Frontiers in Built Environment 5. URL: https://www .frontiersin.org/article/10. 3389/fbuil.2019.00059, doi:10.3389/fbuil.2019.00059.

Jesson, M., Sterling, M., Letchford, C., Baker, C., 2015a. Aerodynamic forces on the roofs of low-, mid- and high-rise buildings subject to transient winds. Journal of Wind Engineering and Industrial Aerodynamics 143, 42-49. 
Jesson, M., Sterling, M., Letchford, C., Haines, M., 2015b. Aerodynamic forces on generic buildings subject to transient, downburst-type winds. Journal of Wind Engineering and Industrial Aerodynamics 137, 58-68.

Laing, A., 2015. Mesoscale convective systems, in: Encyclopaedia of Atmospheric Sciences. 2 ed.. Elsevier. volume 3, pp. 1258-1273.

Li, H., Laima, S., Li, N., Ou, J., Duan, Z., 2010. Correlation analysis of the wind of a cable-stayed bridge based on field monitoring. Wind and Structures, An International Journal 13, 529-556.

Lompar, M., Ćurić, M., Romanic, D., 2018. Implementation of a gust front head collapse scheme in the wrf numerical model. Atmospheric Research 203, 231245. URL: http://www.sciencedirect.com/science/article/pii/ S0169809517309432, doi:https://doi.org/10.1016/j .atmosres.2017. 12.018 .

Meng, X., Nguyen, D., Xie, Y., Owen, J., Psimoulis, P., Ince, S., Chen, Q., Ye, J., Bhatia, P., 2018. Design and implementation of a new system for large bridge monitoring-geoshm. Sensors 18, 775. URL: http: //www.mdpi.com/ 1424-8220/18/3/775, doi:doi:10.3390/s18030775.

Met Office, 2003. $1 \mathrm{~km}$ Resolution UK Composite Rainfall Data from the Met Office Nimrod System. NCAS British Atmospheric Data Centre, 18/08/2017. http://catalogue.ceda.ac.uk/uuid/27dd6ffba67f667a18c62de5c3456350.

Met Office, 2015. Met Office MSLP Charts images June 2014 to present from the Met Office's SWIFT system. NCAS British Atmospheric Data Centre, 18/08/2017. http://catalogue.ceda.ac.uk/uuid/022a3d5ba0204c4c9bbe983b437289b7.

Mishra, A.R., James, D.L., Letchford, C.W., 2008. Physical simulation of a single-celled tornado-like vortex, part b: Wind loading on a cubical model. Journal of Wind Engineering and Industrial Aerodynamics 96, 1258-1273.

Orf, L., Kantor, E., Savory, E., 2012. Simulation of a downburst-producing thunderstorm using a very high-resolution three-dimensional cloud model. Journal of Wind Engineering and Industrial Aerodynamics 104-106, 547-557. 
Orf, L.G., Oreskovic, C., Savory, E., Kantor, E., 2014. Circumferential analysis of a simulated three-dimensional downburst-producing thunderstorm outflow. Journal of Wind Engineering and Industrial Aerodynamics 135, 182-190.

Owen, J.S., 2020. Forth road bridge location map. [PDF map], Scale 1:40000, VectorMap District [ geospatial data], Updated: November 2017, Ordnance Survey (GB), Using: EDINA Digimap Ordnance Survey Service, ¡http://digimap.edina.ac.uk/¿, Created: August 2020.

Parker, D.J., 2015. Mesoscale meteorology - overview, in: Encyclopedia of Atmospheric Sciences. 2 ed.. Elsevier. volume 3, pp. 316-322.

Rauber, R.M., Ramamurthy, M., 2015. Mesoscale meteorology — cloud and precipitation bands, in: Encyclopedia of Atmospheric Sciences. 2 ed.. Elsevier. volume 3, pp. 323-330.

Refan, M., Hangan, H., 2018. Near surface experimental exploration of tornado vortices. Journal of Wind Engineering and Industrial Aerodynamics 175, 120 135. URL: http://www.sciencedirect.com/science/article/pii/ S0167610517304956, doi:https://doi.org/10.1016/j.jweia.2018.01. 042.

Romanic, D., LoTufo, J., Hangan, H., 2019. Transient behavior in impinging jets in crossflow with application to downburst flows. Journal of Wind Engineering and Industrial Aerodynamics 184, 209227. URL: http://www.sciencedirect.com/science/article/pii/ S0167610518303854, doi:https://doi.org/10.1016/j.jweia.2018.11. 020.

Rotunno, R., 2015. Mesoscale meteorology — gust fronts, in: Encyclopedia of Atmospheric Sciences. 2 ed.. Elsevier. volume 3, pp. 331-333.

Sherman, D.J., 1987. The passage of a weak thunderstorn downburst over an instrumented tower. Monthly Weather Review 115, 1193 1205. URL: https://doi.org/10.1175/1520-0493(1987) 115<1193: TPOAWT>2.0.CO;2, doi:10.1175/1520-0493(1987) 115<1193: tpoawt>2. $0 . \operatorname{co} ; 2$.

Tao, T., Wang, H., 2019. Modelling of longitudinal evolutionary power spectral density of typhoon winds considering high-frequency subrange. Journal of 
Wind Engineering and Industrial Aerodynamics 193, 103957. URL: http:// www.sciencedirect.com/science/article/pii/S0167610519305483, doi:https://doi.org/10.1016/j.jweia.2019.103957.

Tao, T., Wang, H., Wu, T., 2017. Comparative study of the wind characteristics of a strong wind event based on stationary and nonstationary models. Journal of Structural Engineering 143, 04016230. URL: https: //ascelibrary. org/doi/abs/10.1061/\%28ASCE\%29ST . 1943-541X.0001725, doi:doi:10. 1061/(ASCE) ST . 1943-541X .0001725.

Wang, H., Wu, T., Tao, T., Li, A., Kareem, A., 2016. Measurements and analysis of non-stationary wind characteristics at sutong bridge in typhoon damrey. Journal of Wind Engineering and Industrial Aerodynamics 151, 100-106.

Weisman, M.L., 2015. Mesoscale meteorology — bow echoes and derecho, in: Encyclopedia of Atmospheric Sciences. 2 ed.. Elsevier. volume 3, pp. 384-394.

Zhang, S., Solari, G., De Gaetano, P., Burlando, M., Repetto, M.P., 2017. A refined analysis of thunderstorm outflow characteristics relevant to the wind loading of structures. Probabilistic Engineering Mechanics . 
Table 1: UK Met Office classification of synoptic rainfall descriptors in terms of rainfall rate

\begin{tabular}{lll} 
& Rain & Shower \\
\hline Slight & $<0.5 \mathrm{~mm} / \mathrm{h}$ & $<2 \mathrm{~mm} / \mathrm{h}$ \\
Moderate & $0.5-4 \mathrm{~mm} / \mathrm{h}$ & $2-10 \mathrm{~mm} / \mathrm{h}$ \\
Heavy & $>4 \mathrm{~mm} / \mathrm{h}$ & $10-50 \mathrm{~mm} / \mathrm{h}$ \\
Violent & & $>50 \mathrm{~mm} / \mathrm{h}$
\end{tabular}


Table 2: Maximum values of rainfall rate from rainfall radar data between 00:00 UTC and 01:00 UTC of January $9^{\text {th }} 2015$

\begin{tabular}{lrr} 
Time $(\mathrm{UTC})$ & FRB $(\mathrm{mm} / \mathrm{h})$ & $\mathrm{UK}(\mathrm{mm} / \mathrm{h})$ \\
\hline $00: 00$ & 29.6 & 74.7 \\
$00: 05$ & 75.8 & N/A \\
$00: 10$ & 43.3 & 72.8 \\
$00: 15$ & 54.0 & 60.5 \\
$00: 20$ & 51.3 & 138.8 \\
$00: 25$ & 100.7 & 102.1 \\
$00: 30$ & 133.0 & 133.0 \\
$00: 35$ & 94.3 & 175.1 \\
$00: 40$ & 78.3 & 131.4 \\
$00: 45$ & 109.1 & 134.3 \\
$00: 50$ & 154.3 & 154.3 \\
$00: 55$ & 80.3 & 128.0 \\
$01: 00$ & 65.7 & 139.6
\end{tabular}




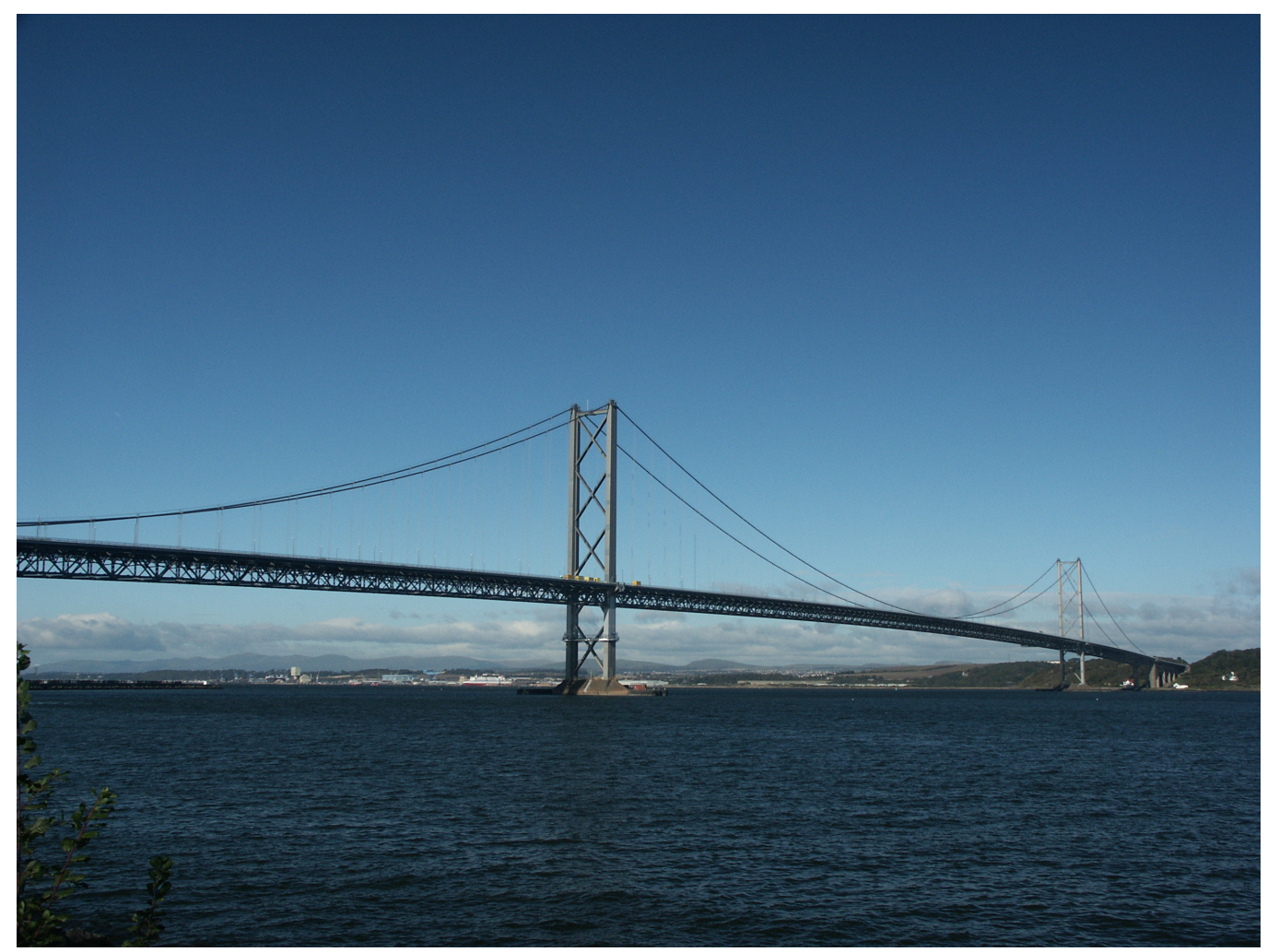

Figure 1: The Forth Road Bridge after Stuart Halliday $\left[\begin{array}{llll}C & B Y & 3.0\end{array}\right.$ (https://creativecommons.org/licenses/by/3.0)] 

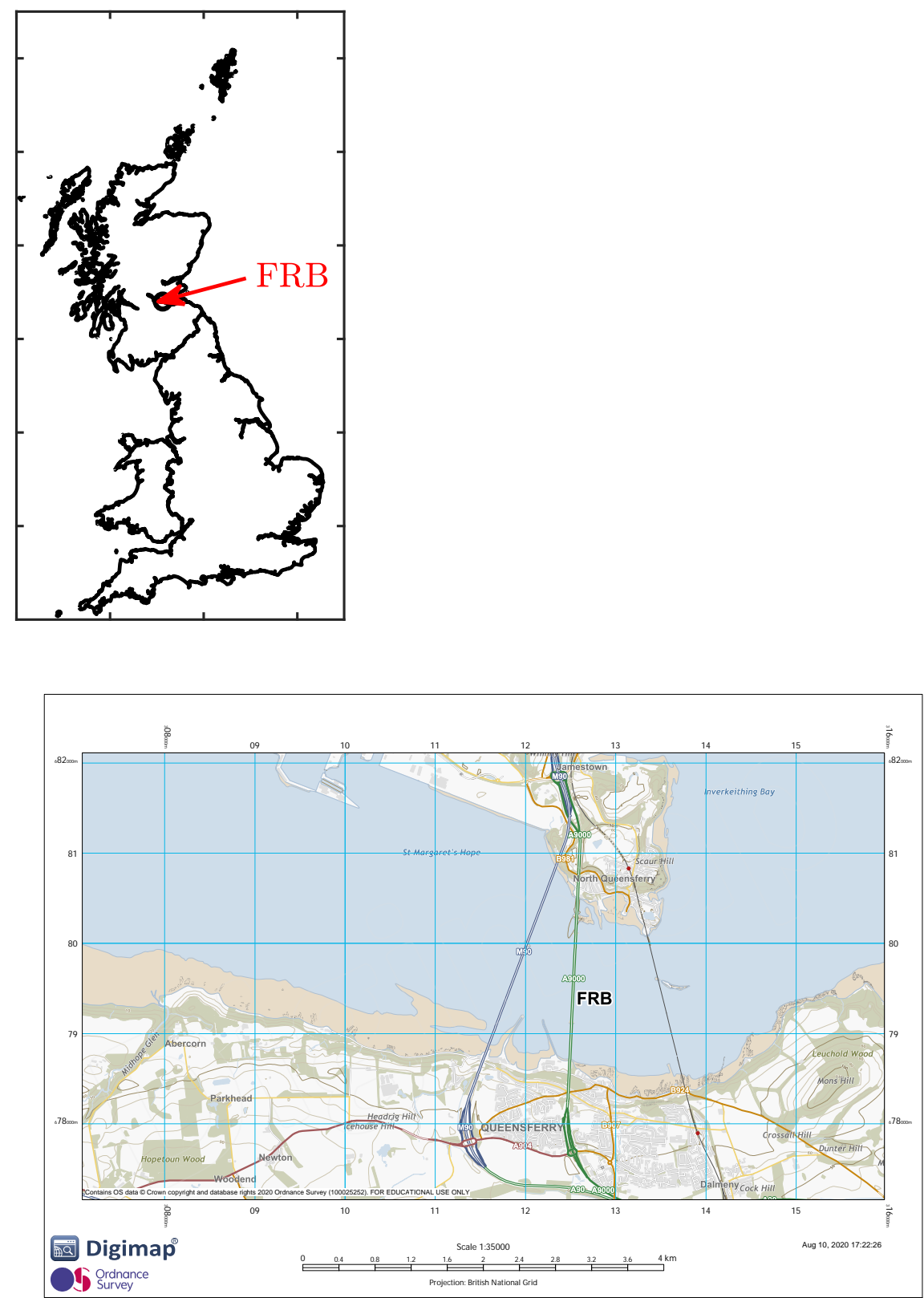

Figure 2: The location of the Forth Road Bridge (a) United Kingdom map showing location (N $56^{\circ} 0.0778 \mathrm{~W} 3^{\circ} 24.2402^{\prime}$ ) (b) Local map showing FRB in context (Owen, 2020). The FRB axis runs $2.67^{\circ}$ off north-south. 


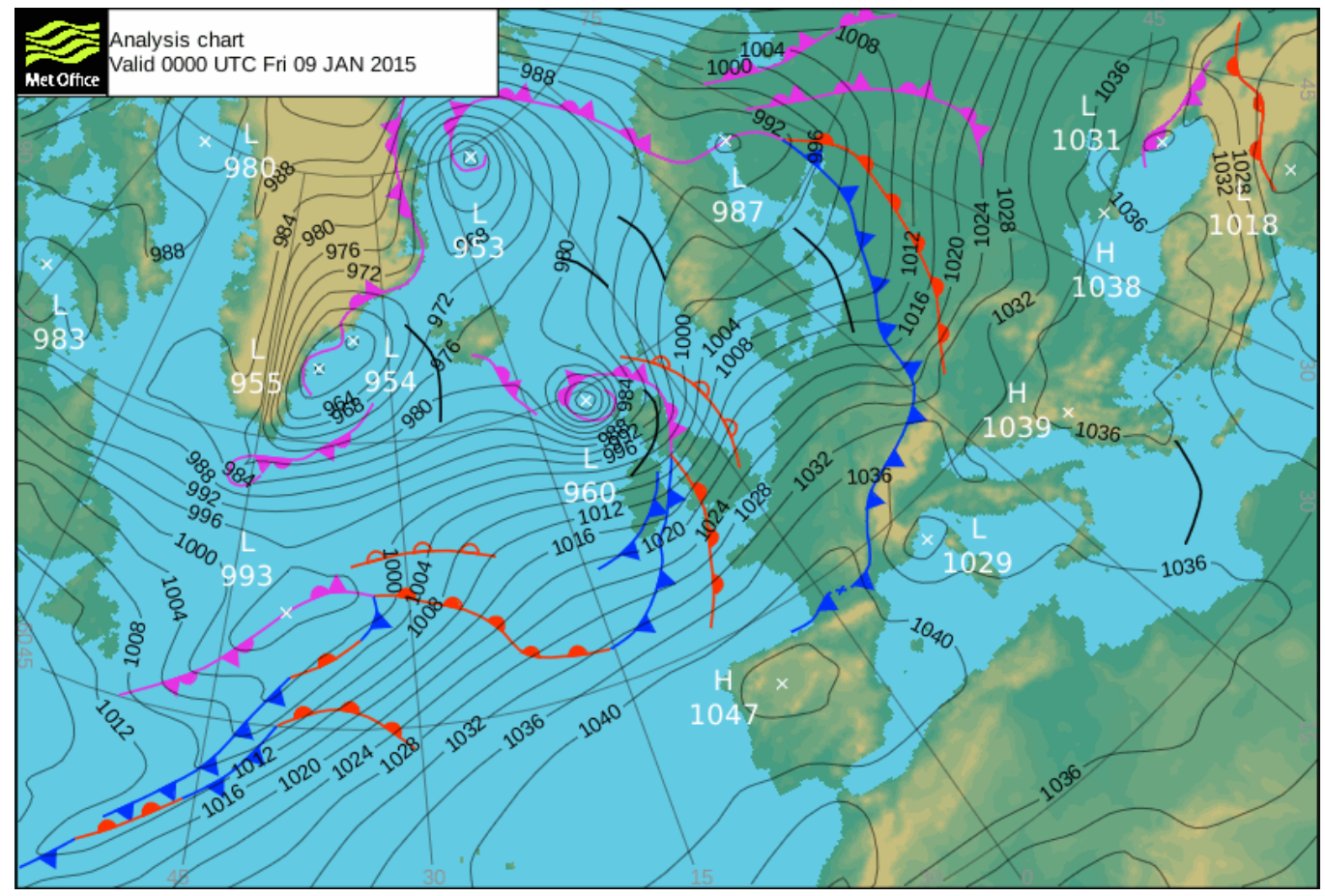

Figure 3: Surface Pressure Chart for 00:00 UTC on $9^{\text {th }}$ January 2015 showing the depression (Storm Elon) to the North West of Scotland responsible for the strong winds at the Forth Road Bridge location (Met Office, 2015). 


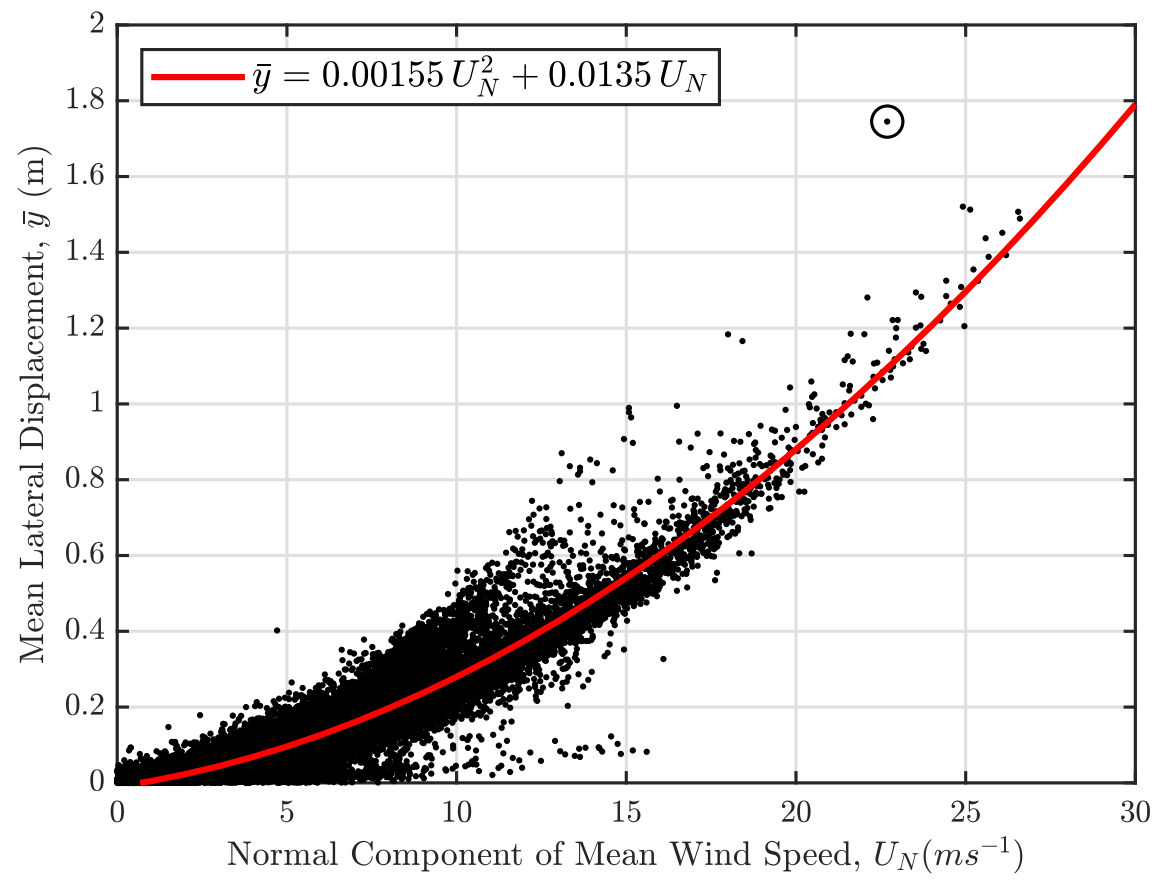

(a)

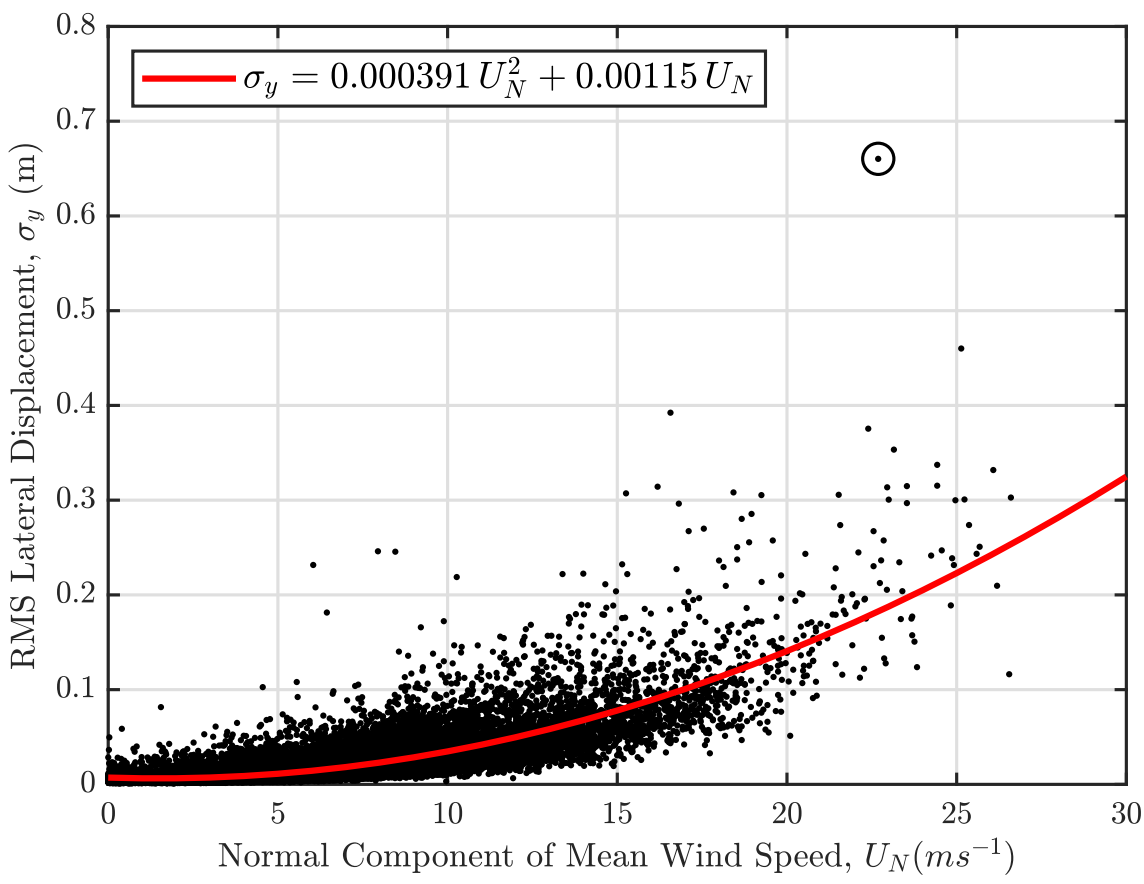

(b) 


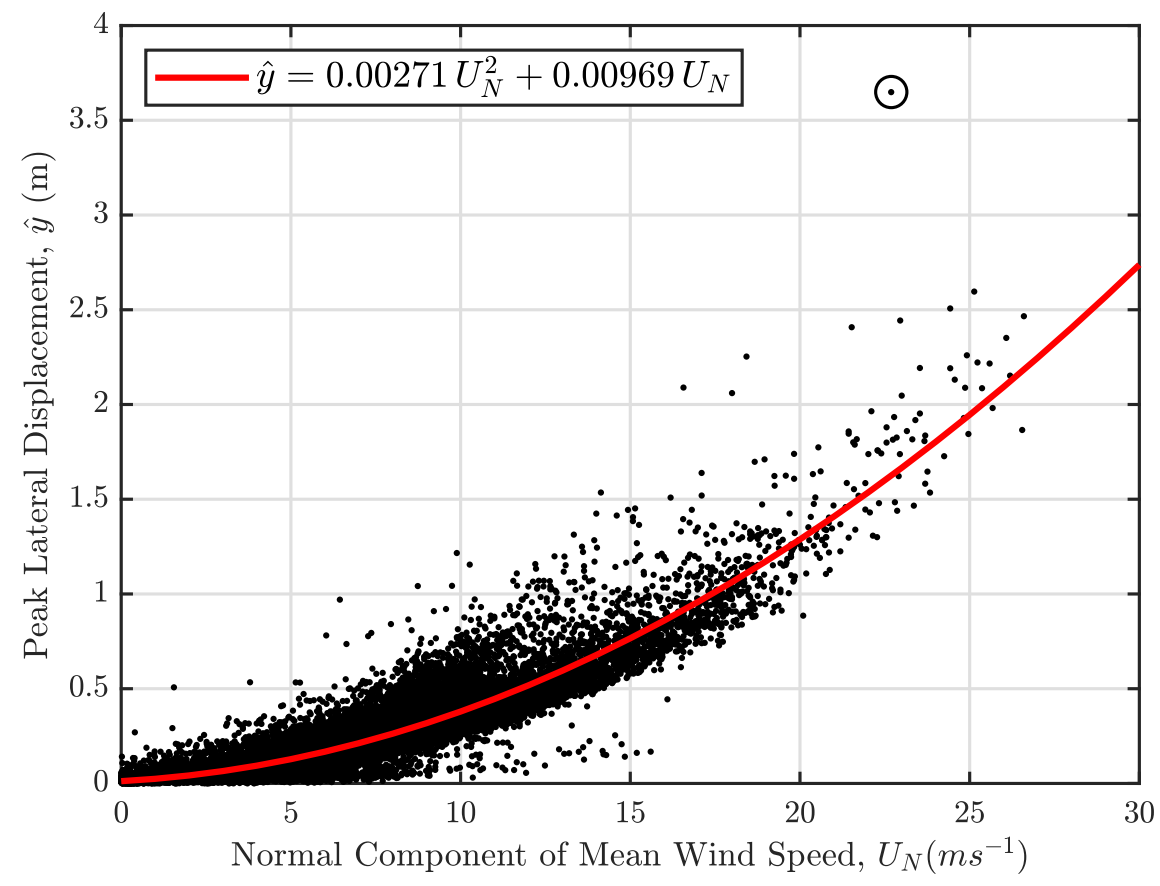

(c)

Figure 4: Variation of lateral displacement at midspan with normal component of mean wind speed for the year 2015, (a) 10 minute mean (b) 10 minute RMS and (c) 10 minute maximum. A second order trend line is included to indicate the expected quadratic relationship with wind speed. Note the anomalous response is circled in each chart. 

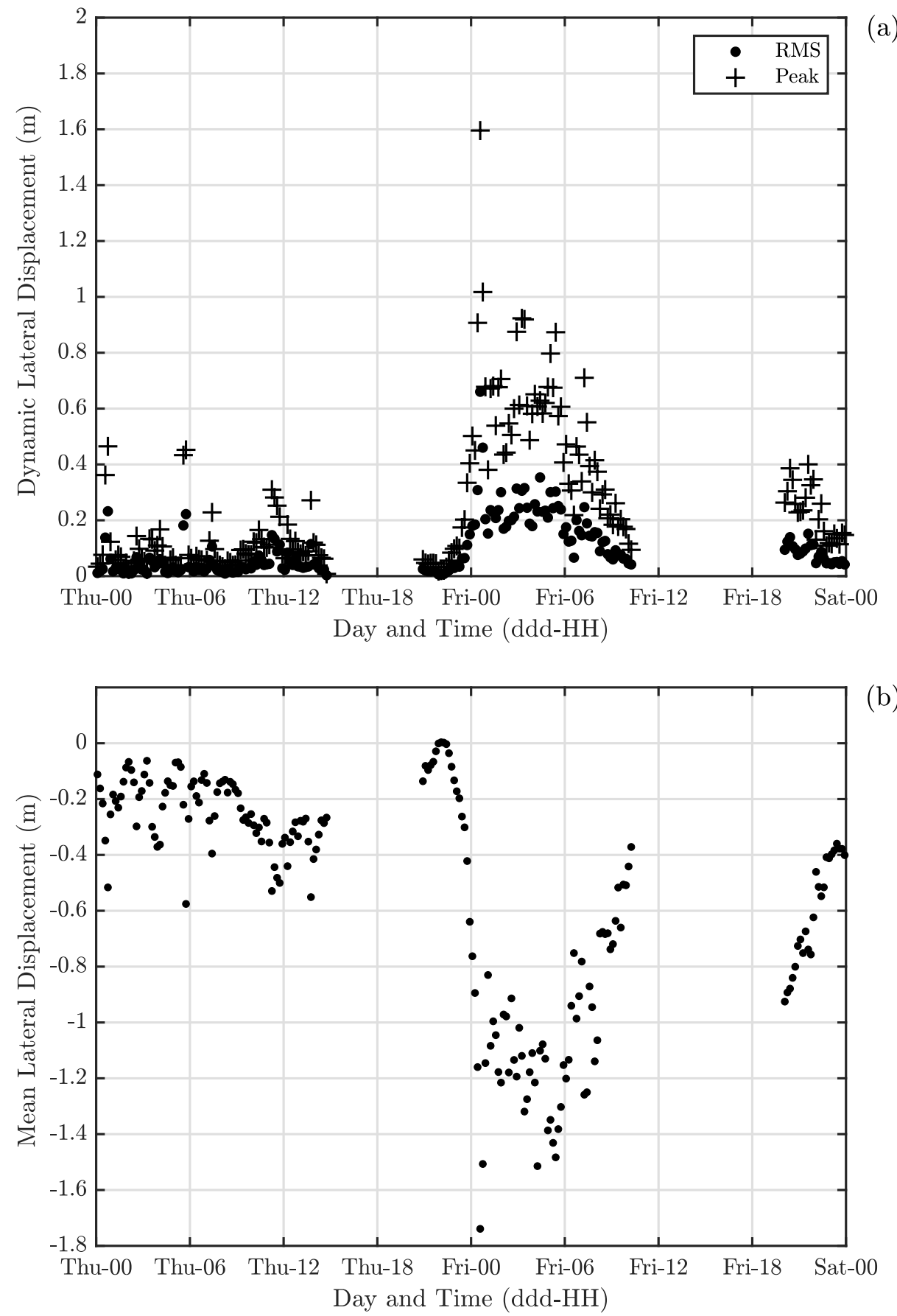

Figure 5: Variation of lateral displacement during January $8^{\text {th }}$ and $9^{\text {th }} 2015$, (a) RMS and peak response found from ten minute window by removing the one minute moving average (b) mean response found from a ten minute window. 


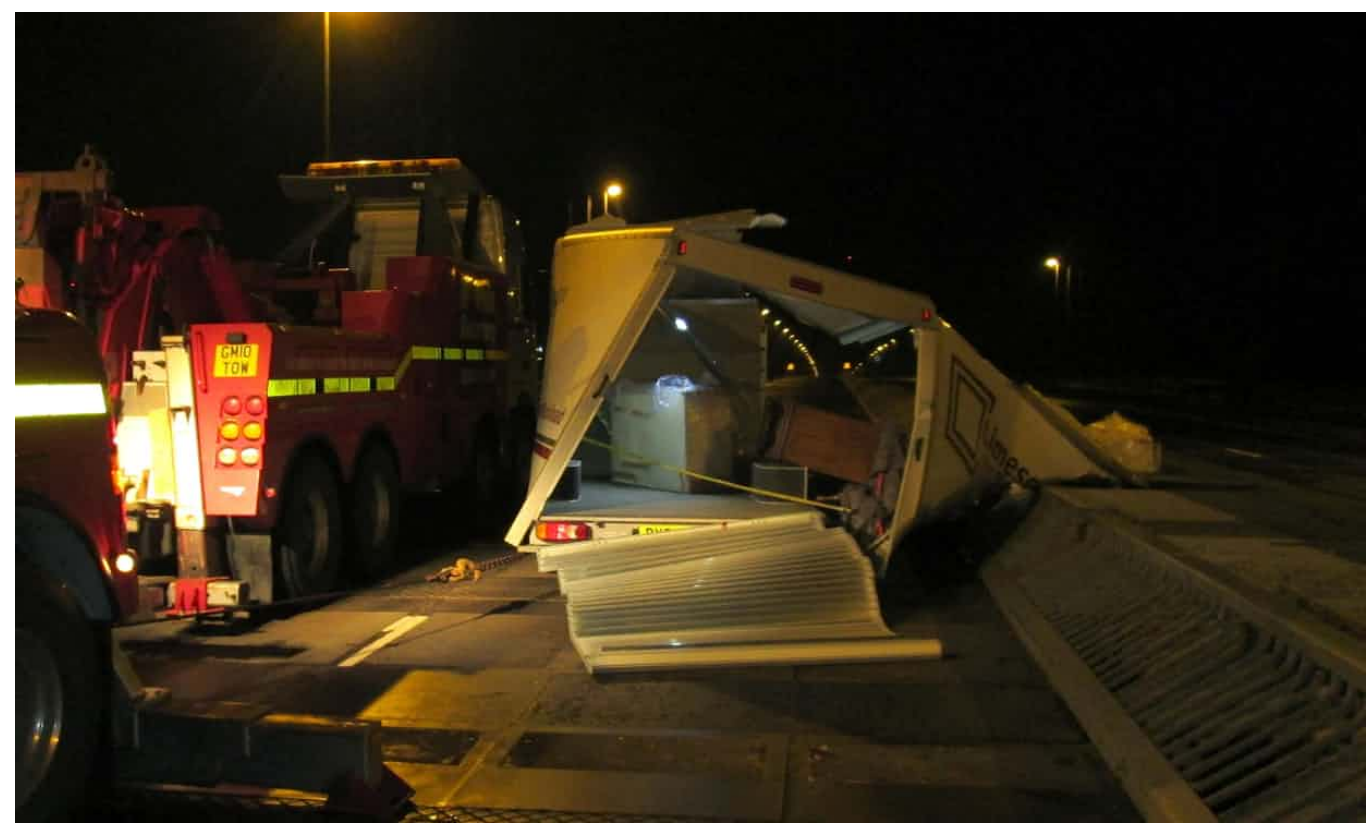

Figure 6: Press image of van reported blown over on the FRB at 00:36 UTC on $9^{\text {th }}$ January 2015 


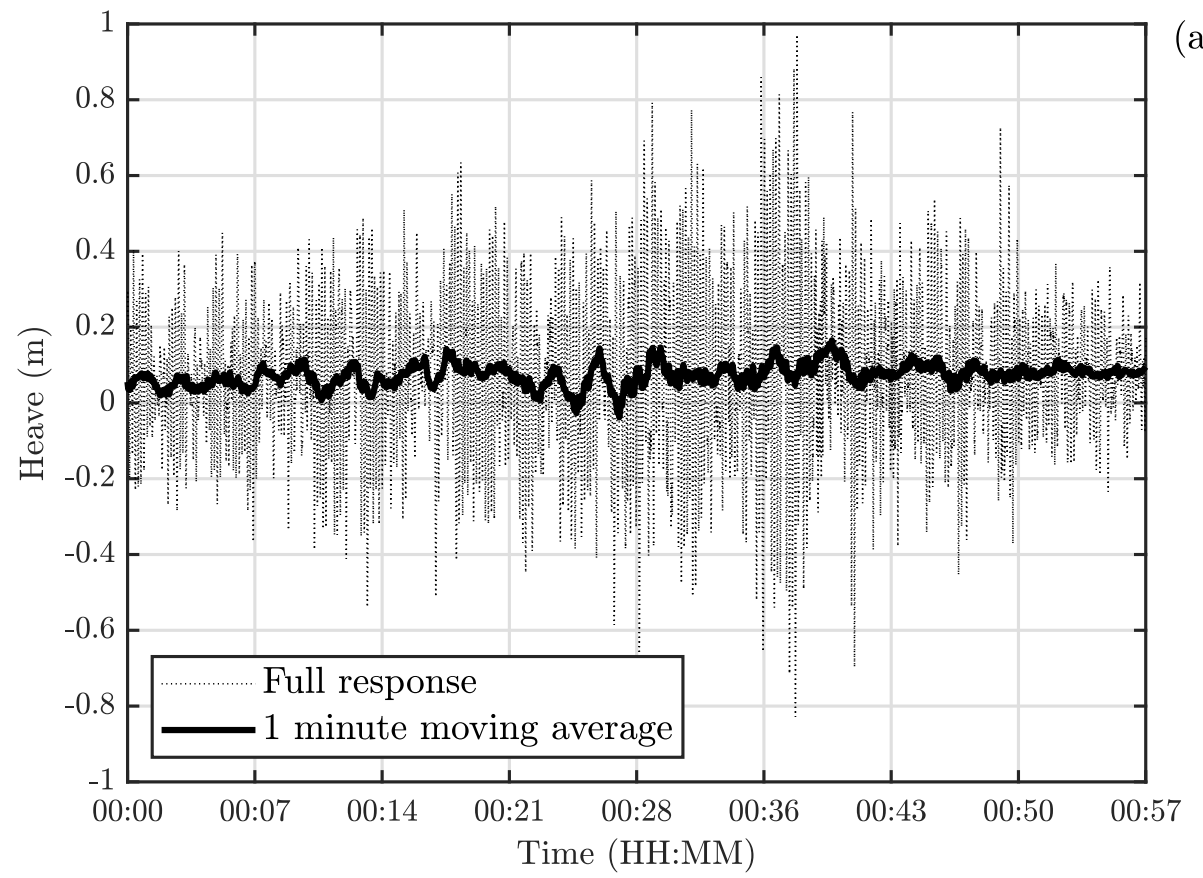

(a)

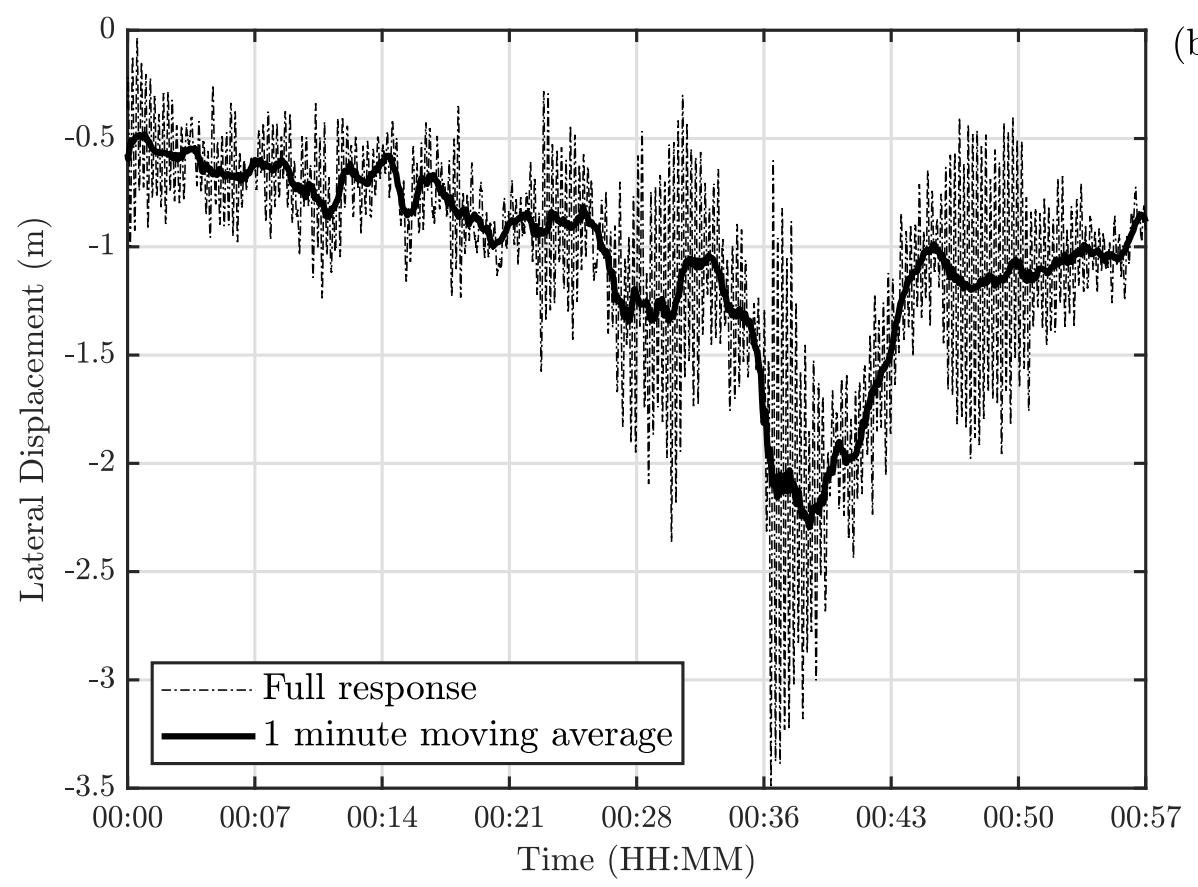

(b)

Figure 7: Bridge response between 00:00 UTC and 01:00 UTC on $9^{\text {th }}$ January 2015 (a) heave (b) lateral displacement. 

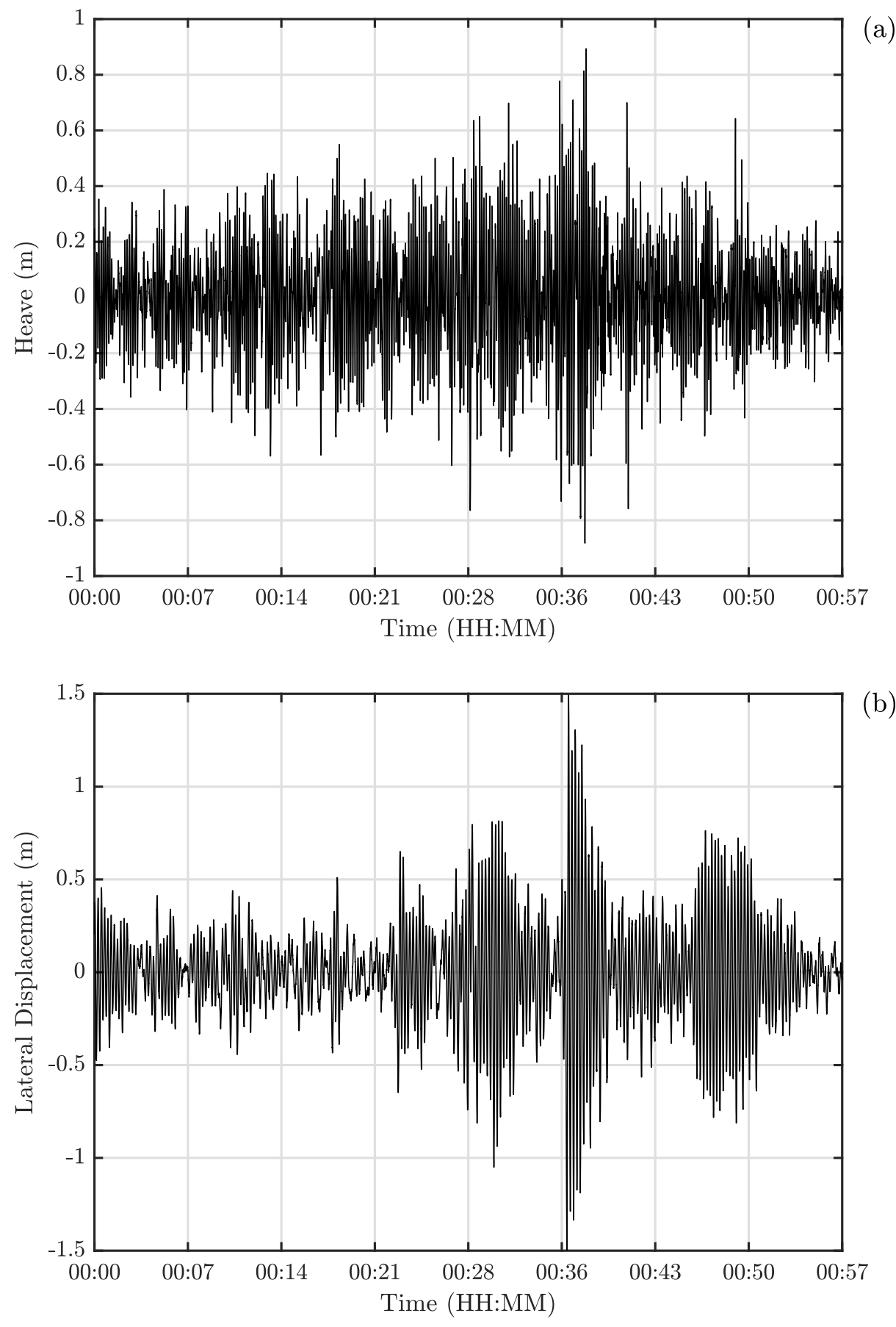

(b)

Figure 8: Dynamic component of the bridge response between 00:00 UTC and 01:00 UTC on $9^{\text {th }}$ January 2015 (a) heave (b) lateral displacement. 

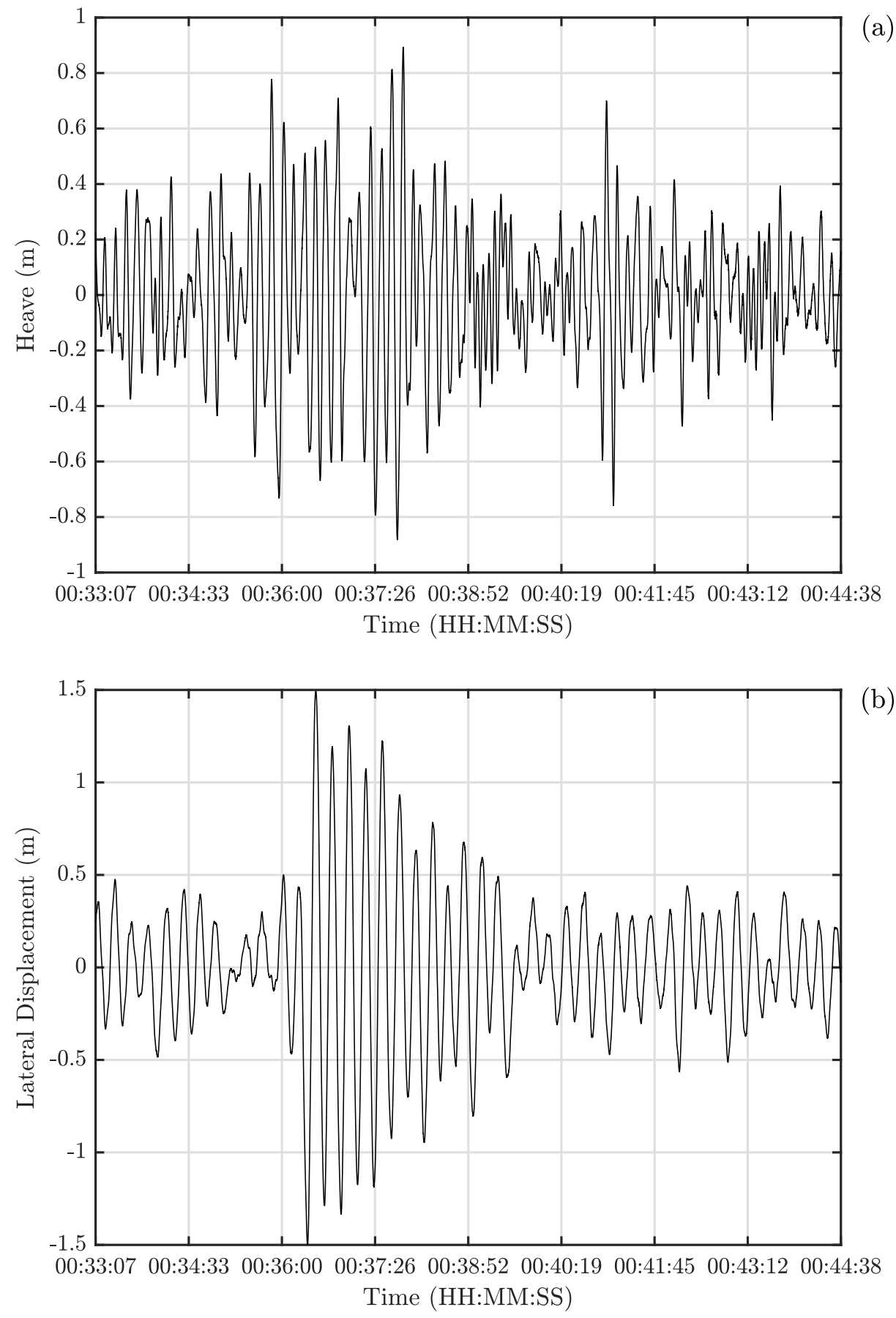

Figure 9: Dynamic component of the bridge response showing response to significant gust event (a) heave (b) lateral displacement. 


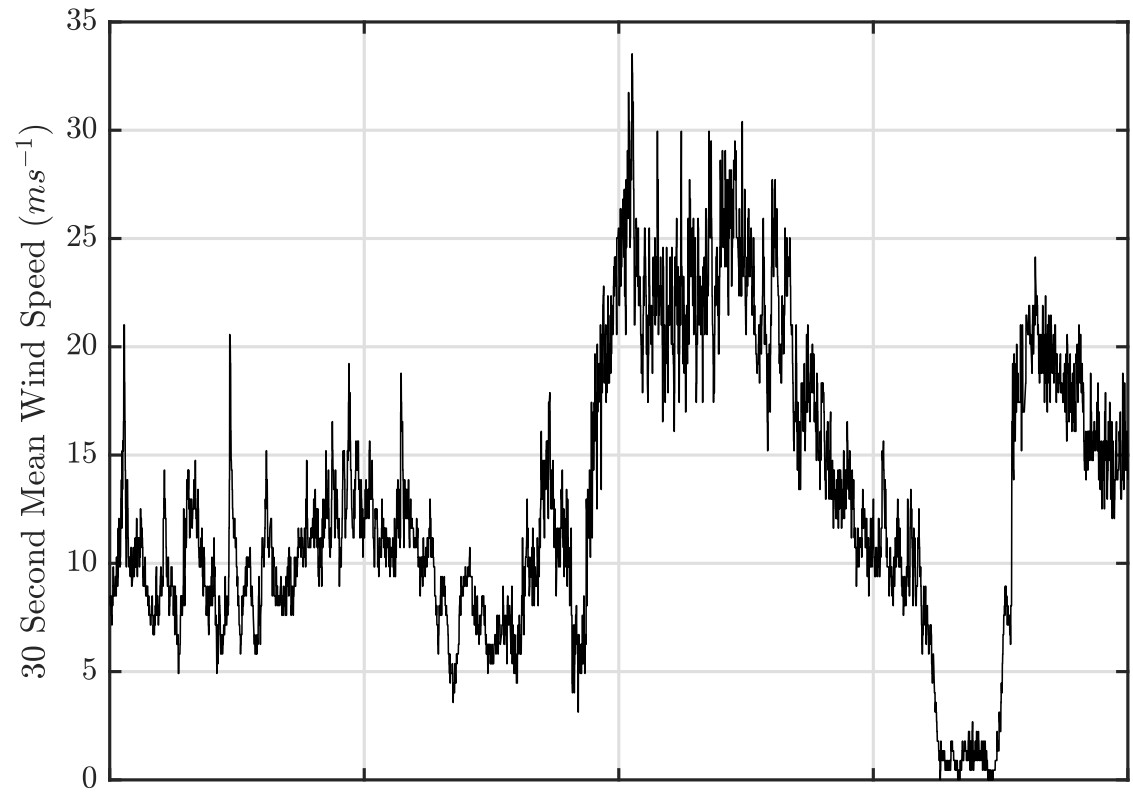

(a)

Thu 08/01 00:00 Thu 08/01 12:00 Fri 09/01 00:00 Fri 09/01 12:00 Sat 10/01 00:00 Day, date and time

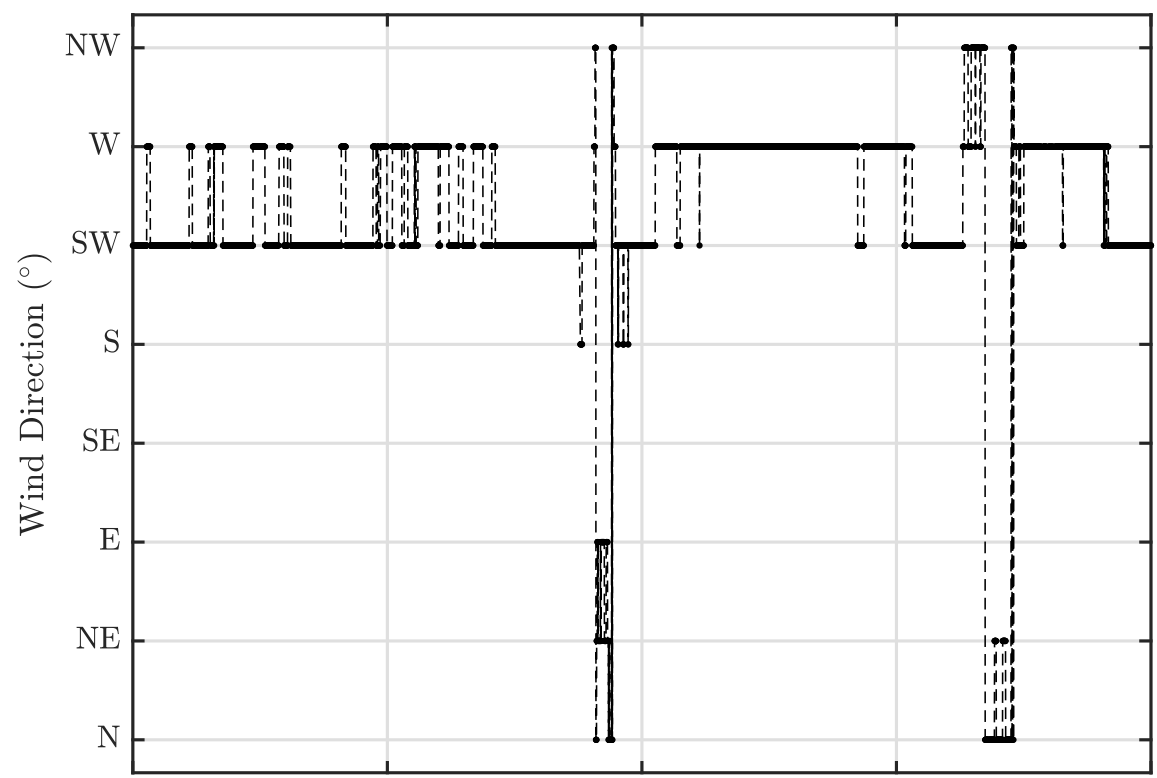

(b)

Thu 08/01 00:00 Thu 08/01 12:00 Fri 09/01 00:00 Fri 09/01 12:00 $\quad$ Sat 10/01 00:00 Day, date and time

Figure 10: Wind data for January $8^{\text {th }}$ and $9^{\text {th }}$ January 2015 (a) 30 second mean wind speed $(b) 30$ second mean wind direction. 
(a)
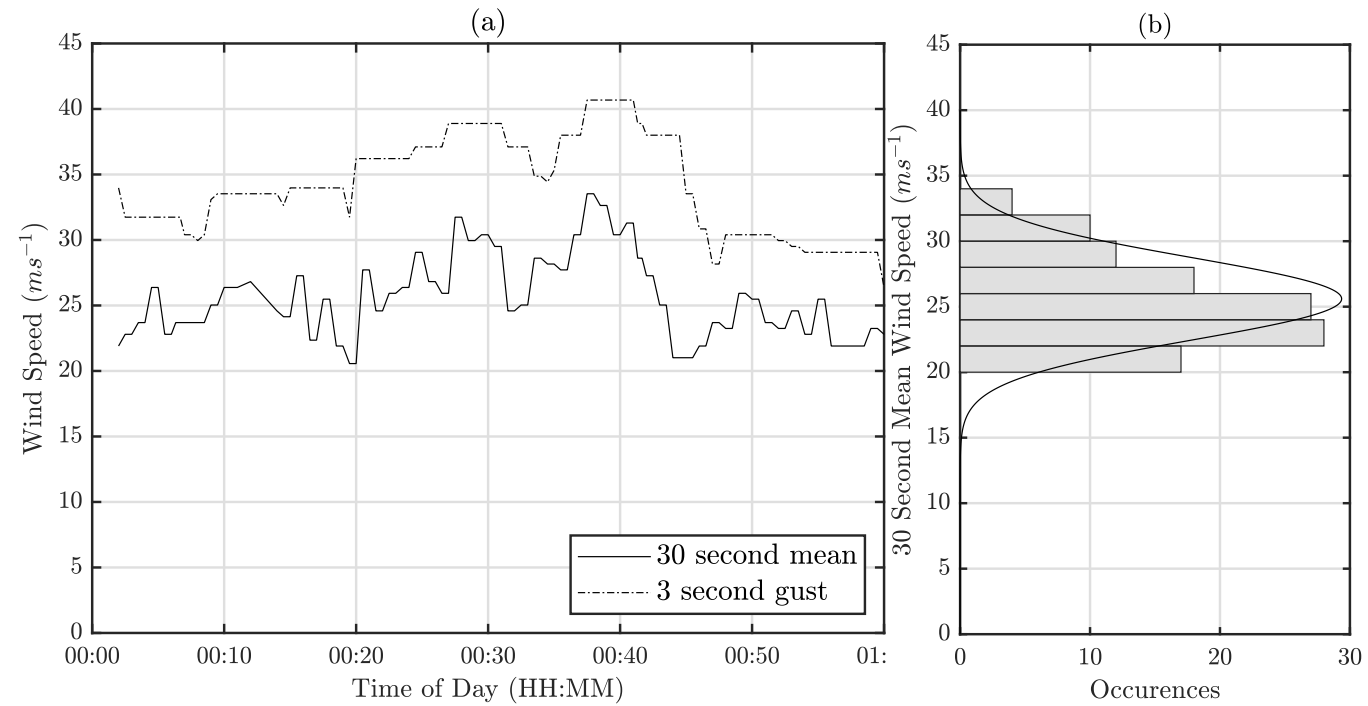

(c)

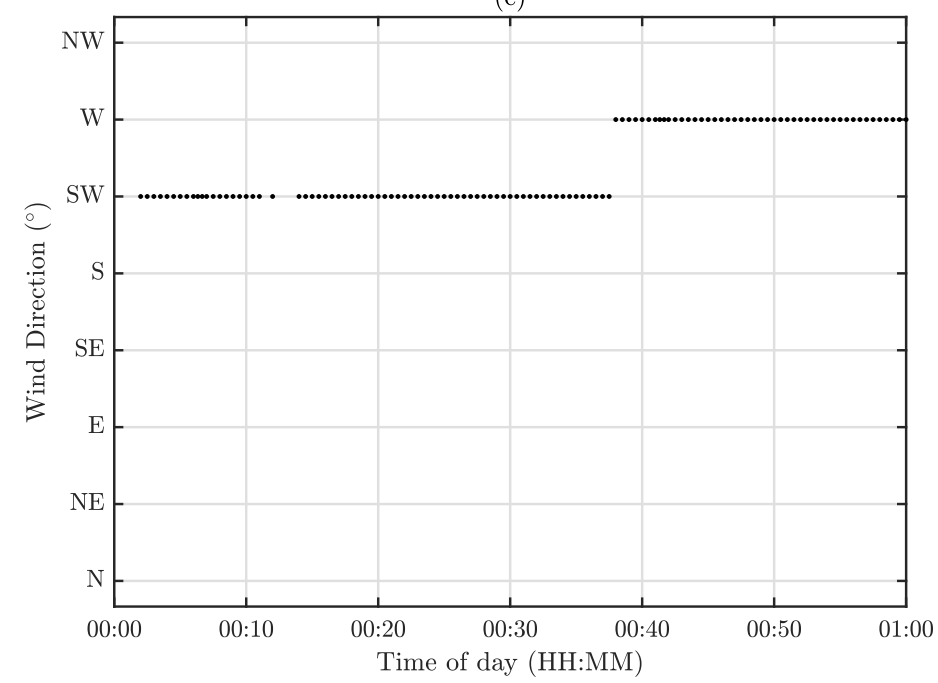

Figure 11: Wind data between 00:00 UTC and 01:00 UTC on $9^{\text {th }}$ January 2015 (a) wind speed showing 30 second mean and corresponding 3 second gust (b) distribution of 30 second mean wind speed and normal distribution for comparison (c) 30 second mean wind direction. 
9 January 2015 00:15

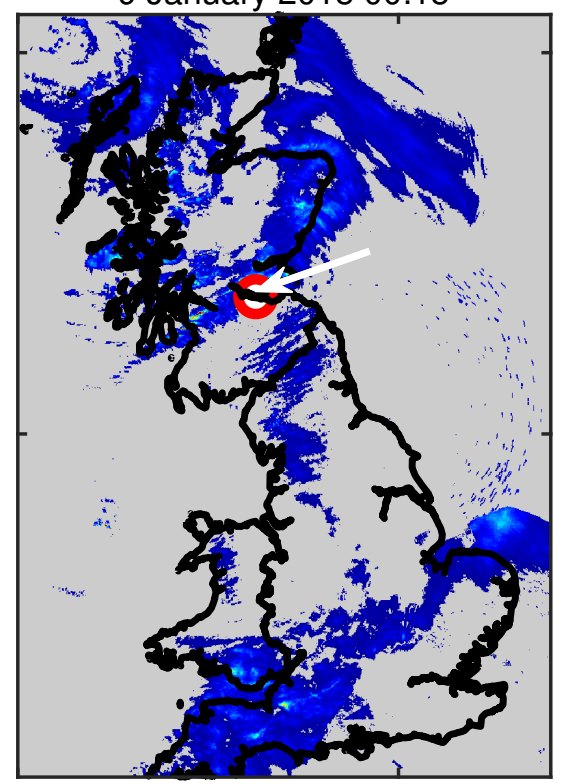

9 January 2015 00:45

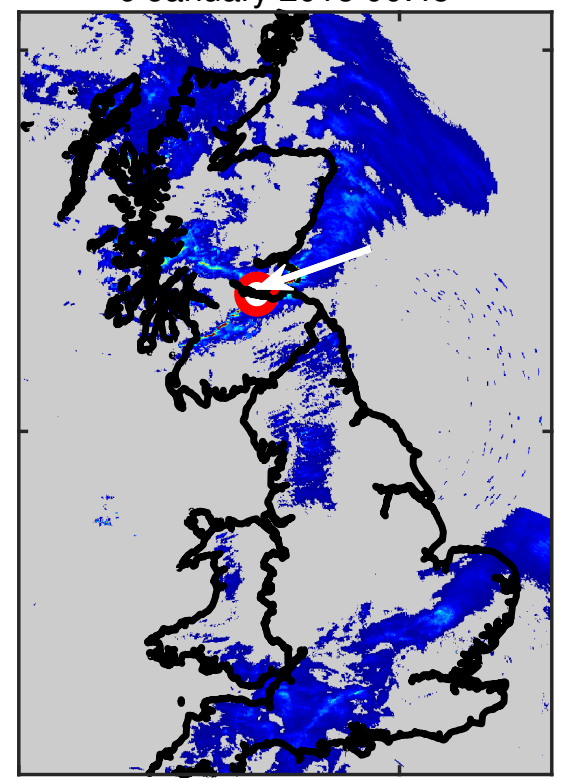

9 January 2015 00:30

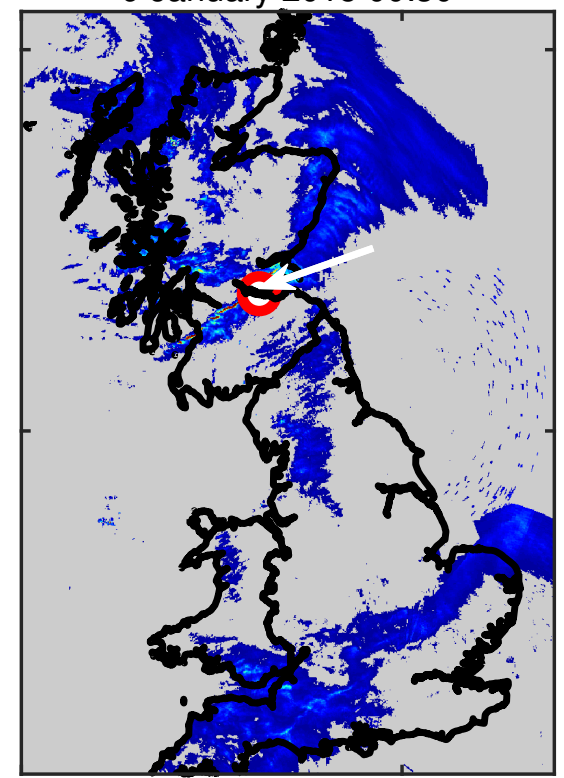

9 January 2015 00:60

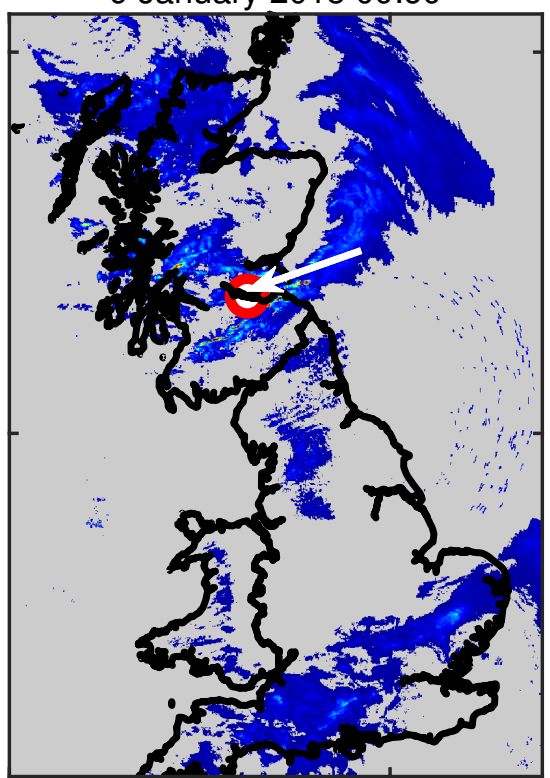

Figure 12: NIMROD composite rainfall radar images, resolution $1 \mathrm{~km}$ square. Images are shown for the whole of GB at 15 minute intervals between 00:15 UTC and 01:00 UTC on January $9^{\text {th }}$ 2015. The location of the FRB is indicated by the red circle and white arrow. (Met Office, 2003) 

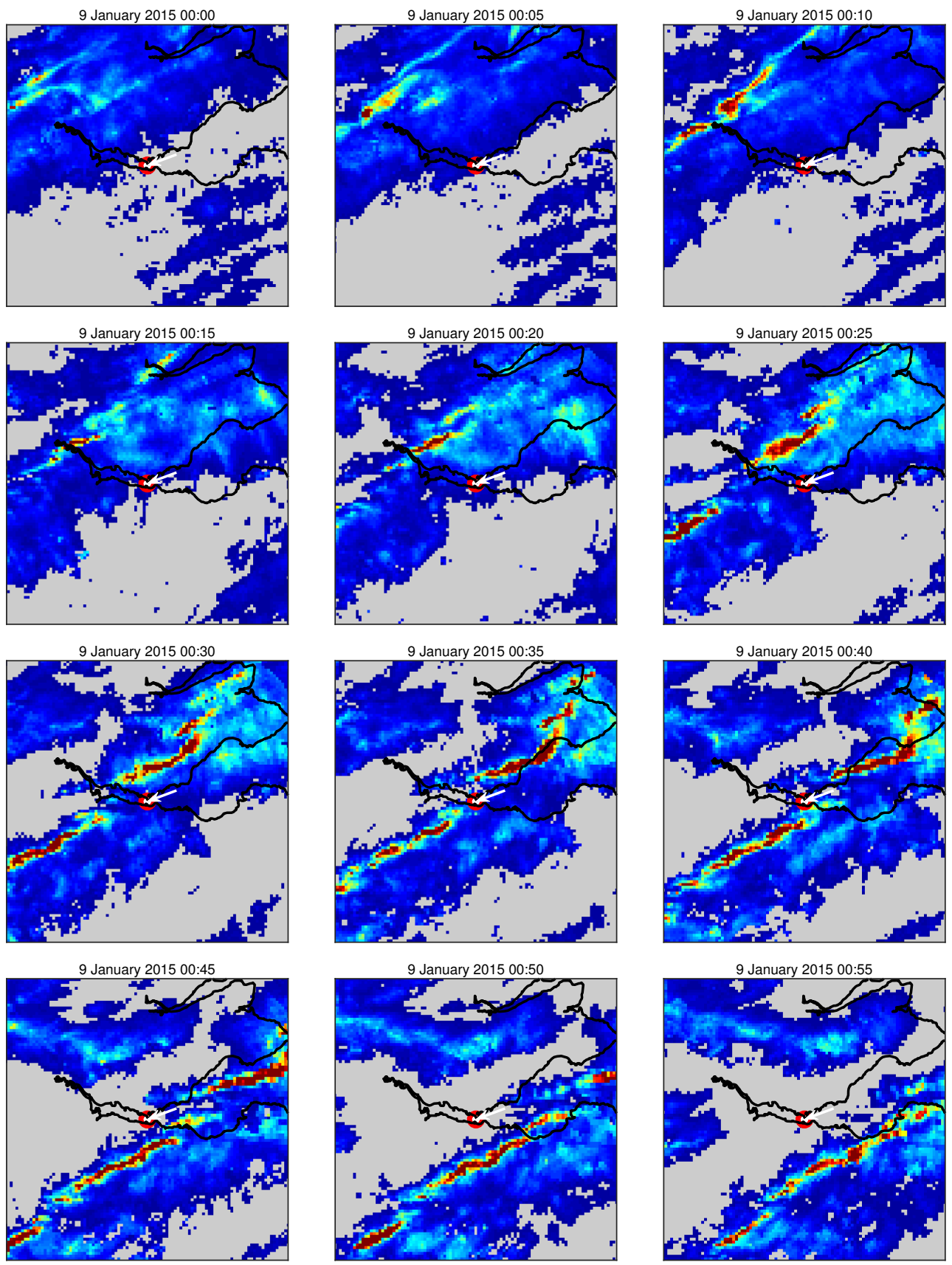

Figure 13: NIMROD composite rainfall radar images, resolution $1 \mathrm{~km}$ square. Images are shown for a region 50km either side of the FRB at 5 minute intervals between 00:00 UTC and 00:55 UTC on January $9^{\text {th }} 2015$. The location of the FRB is shown by the red circle and white arrow. (Met Office, 2003) 


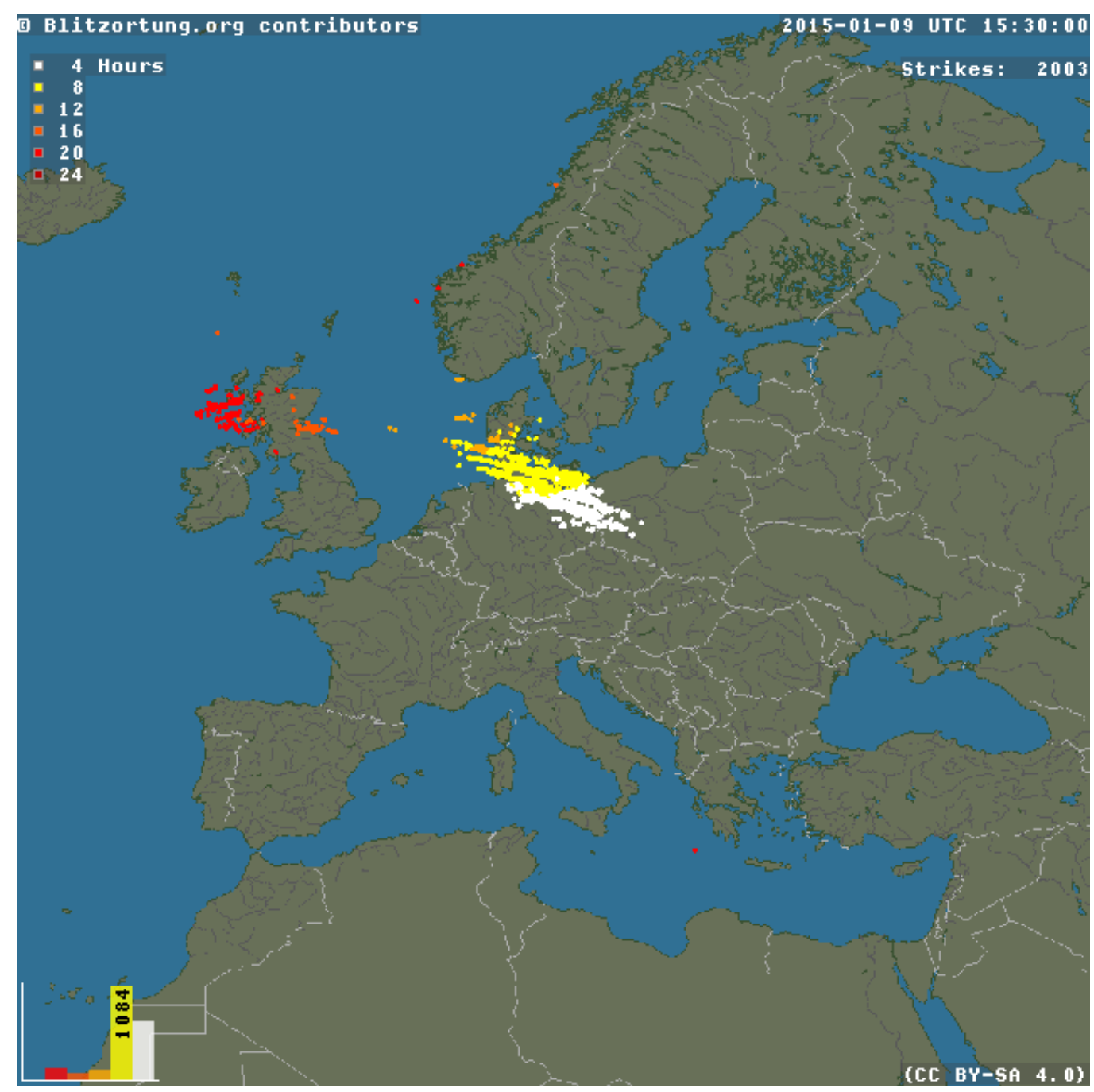

Figure 14: Lightning strikes across Europe for 24 hours to 14:30 UTC on January $9^{\text {th }}$ 2015. Progress of time is shown by the changing colour of the markers. (LightningMaps.org CC BY-SA 4.0/ Lightning data by Blitzortung.org and contributors). 


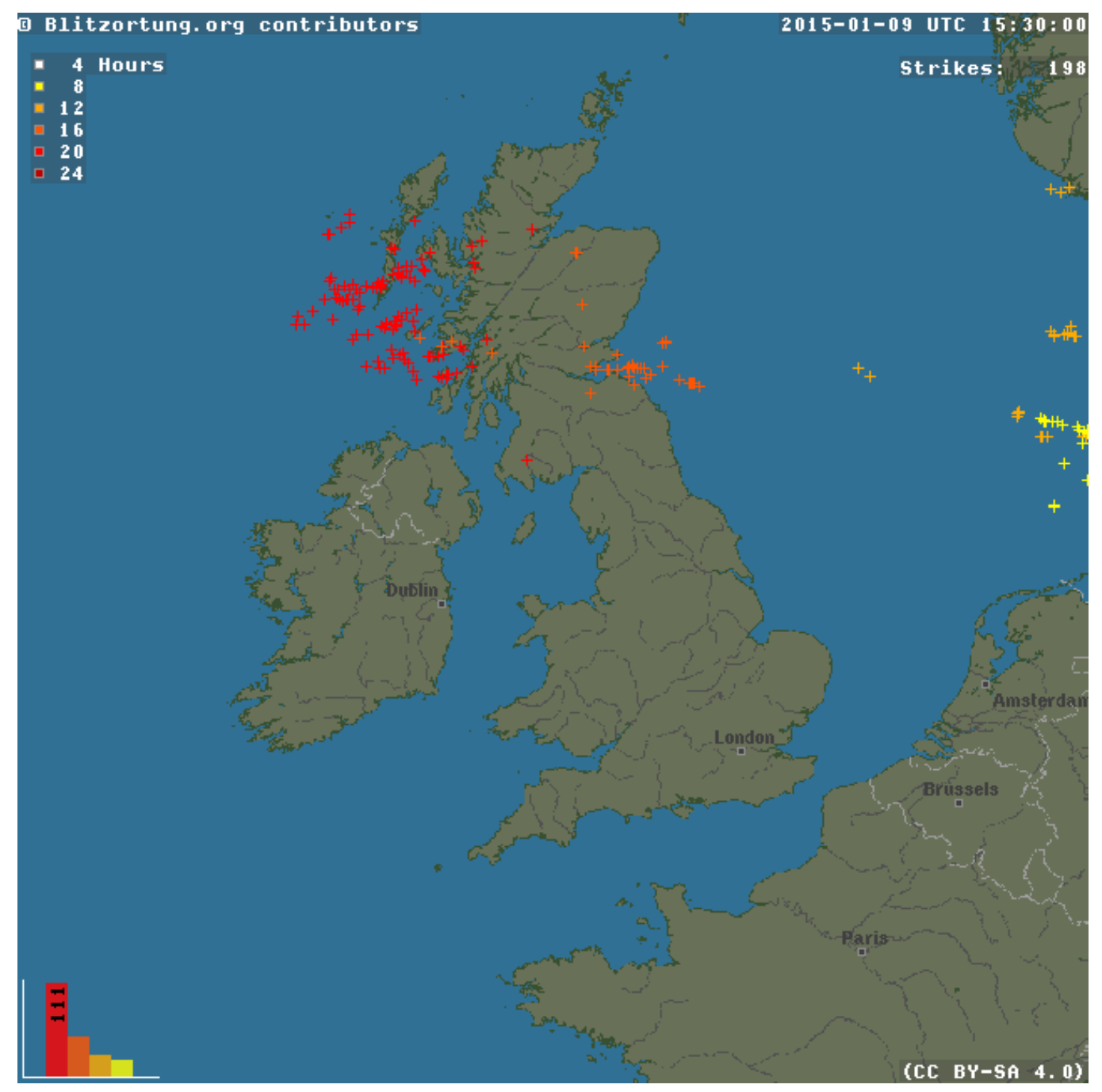

Figure 15: Lightning strikes across UK for 24 hours to 14:30 UTC on January $9^{\text {th }} 2015$. Progress of time is shown by the changing colour of the markers. (LightningMaps.org CC BY-SA 4.0/Lightning data by Blitzortung.org and contributors). 


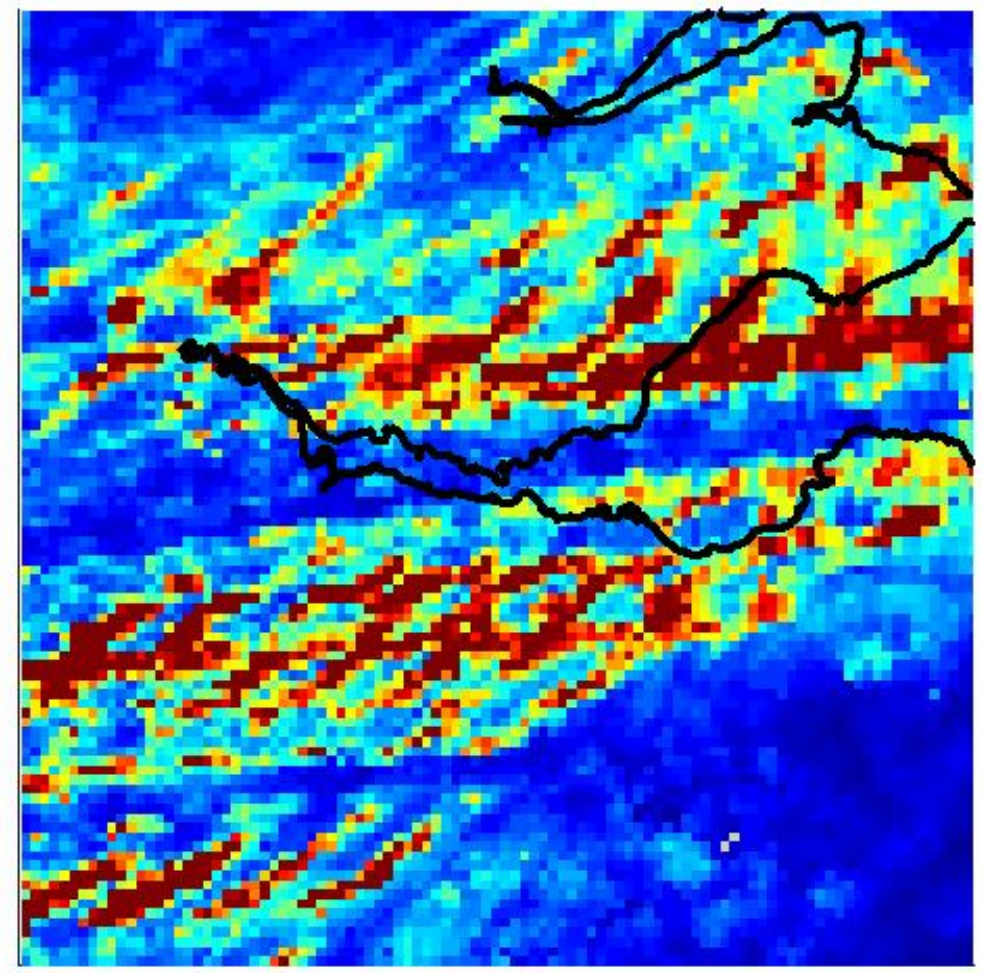

Figure 16: Rainfall radar overlay for 00:00 UTC to 00:55 UTC on January $9^{\text {th }} 2015$. 